\title{
The influence of low permeability layers on the installation and the response to vertical cyclic loading of suction caissons
}

\author{
M. Stapelfeldt ${ }^{1}$, B. Bienen ${ }^{2}$, and J. Grabe ${ }^{3}$ \\ ${ }^{1}$ Institute of Geotechnical Engineering and Construction Management, Hamburg University of \\ Technology, Harburg, Hamburg, Germany, Email: marc.stapelfeldt@tuhh.de \\ ${ }^{2}$ Centre for Offshore Foundation Systems, The University of Western Australia, Crawley, Perth, \\ WA, Australia \\ ${ }^{3}$ Institute of Geotechnical Engineering and Construction Management, Hamburg University of \\ Technology, Harburg, Hamburg, Germany
}

\begin{abstract}
Offshore wind is a key part of the change towards renewable energy sources. Offshore wind farm developments are moving to sites that are characterised by increased water depths and layered soil profiles, e.g. in the North Sea. Suction caisson based jacked structures are expected to be increasingly used to support wind turbines at such sites. Experience of suction caissons serving as foundations for offshore wind turbines is limited. The mechanisms governing the suction caisson installation in layered soils are poorly understood and no published data of the in-service performance of suction caisson jackets supporting offshore wind turbines in layered soils exists. This gap is addressed here through a series of centrifuge tests investigating the installation and the response of suction caissons in layered soils - sand over clay and clay over sand - subjected to vertical cyclic loading into tension. The results reveal the mechanisms enabling suction caisson installation in layered soils and the complex load transfer mechanisms governing the suction caisson response under vertical cyclic loading. The clay layer plays a key role: In sand over clay, it encapsulates the sand plug which leads to predominantly undrained behaviour. In clay over sand, the uplift of the
\end{abstract}


clay soil plug is critical both in facilitating suction installation and in response to vertical cyclic loading in tension. These findings provide confidence towards suction installation and caissons response under vertical cyclic loading into tension in layered soils.

\section{INTRODUCTION}

Offshore wind farm developments are moving from shallow water depths and predominantly sandy sea beds towards deeper water and sea beds that are often characterised by layered soils. Jacket substructures may support the offshore wind turbines (OWTs), and these may be equipped with typically three suction caissons (or suction buckets in a suction bucket jacket) with typical aspect ratios of length $L$ to diameter $D$ between $L / D \approx 0.5$ and $L / D \approx 1$. The wind and wave action is transferred to the suction caissons of a jacket primarily as a vertical push-pull mechanism. This might extend into tension during vertical cyclic loading, depending on the jacket self-weight and the spacing between the caissons (Bienen et al. 2018a).

Suction caissons have been successfully installed in sand over clay (SoC) and clay over sand (CoS) before (Senpere and Auvergne 1982; Tjelta et al. 1986; Watson et al. 2006; Broughton et al. 2013). Hence, Tjelta (2015) concluded that suction caissons can be installed at any location at the North Sea. Since most sea beds in northern Europe experienced the last glacial expansion, soils in this area are usually significantly overconsolidated.

However, the mechanisms governing suction caisson installation in layered soils are not yet fully understood and experience with suction caissons as foundations for OWTs in layered soil is limited to a small number of experimental studies. Results from small scale laboratory tests and centrifuge experiments (Raines et al. 2005; Tran 2005; Watson et al. 2006; Senders and Randolph 2007; Cotter 2010) in different soil layer profiles indicated that a low permeability layer underlying sand essentially leads to suction caisson installation that is similar to that in homogeneous clay. A low permeability layer was found to prevent seepage flow in the underlying sand, which eventually leads to premature refusal. However, Tran (2005) and Tran et al. (2007) suggested that uplift of the clay plug might transfer the suction pressure into the underlying sand. Consequently, seepage is expected to reduce the skirt tip resistance, which facilitates the installation. 
Ragni et al. (2020) investigated suction caisson installation into layered soil through centrifuge tests of a half-model caisson against a transparent window with particle image velocimetry (PIV) (Stanier and White 2013; Stanier et al. 2016) to reveal the underlying mechanisms, building on earlier tests in sand (Ragni et al. 2018; Ragni et al. 2019). This study found the suction caisson installation in SoC to be unproblematic and identified the plug uplift in $\mathrm{CoS}$ as the key mechanism to transfer suction pressure to the underlying sand. A high pumping flow rate was found to be beneficial regarding the achievable skirt penetration depth. Plug uplift did not necessarily lead to premature refusal. The clay layer in this study was relatively soft and the investigation limited to the installation phase.

Jeong et al. (2018) and Zografou et al. (2019) among others performed centrifuge tests on suction caisson foundations subjected to vertical cyclic loading in homogeneous sand or clay, respectively. Zhu et al. (2017), Zhu et al. (2018a), and Zhu et al. (2018b) published the only existing centrifuge test on suction caisson foundations embedded in $\mathrm{SoC}$ and subjected to cyclic loading. However, monopod caissons and therefore combined lateral and momentum loading were addressed. The authors are not aware of published data of suction caisson response in layered soils under vertical cyclic loading.

This paper therefore aims to investigate suction caisson installation into SoC and $\mathrm{CoS}$ and the response under subsequent vertical cyclic loading through centrifuge tests, with loading conditions typical for suction caisson jackets supporting OWTs. Full model tests are complemented by half model tests against a transparent window with PIV post-analyses of the images captured to reveal the underlying mechanisms.

\section{EXPERIMENTAL ARRANGEMENT AND TESTING PROCEDURE}

The experiments were performed at $100 g$ in the Acutronic Model 661 centrifuge (Randolph et al. 1991; Randolph and Gaudin 2017) at the University of Western Australia.

\section{Soil sample and pore fluid preparation}

Overconsolidated stiff clay and dense sand are used in this study, which is realistic and creates the most onerous conditions for suction caisson installation. Table 1 and 2 summarise the soil 
properties of the very fine silica sand and kaolin clay used in the centrifuge tests. Layered soil samples with a thickness of the top layer of $20 \mathrm{~mm}$ were prepared to create onerous conditions for suction caisson installation while facilitating comparison to previous studies (Zhu et al. 2018a; Ragni et al. 2020).

The clay was prepared from slurry at a water content of $w \approx 120 \%$, mixed under vacuum, and consolidated in a hydraulic press under a vertical pressure of $\sigma_{v}=350 \mathrm{kPa}$.

Two SoC samples (one for the full model tests and one for the PIV test) were prepared by pluviation of dry sand into the strongbox from a height of approximately $1.2 \mathrm{~m}$ by means of an automatic pluviator, which contained the over consolidated clay layer. The clay layer height was approximately $140 \mathrm{~mm}$ after consolidation. The sand layer was vacuum levelled to a target height of $20 \mathrm{~mm}$ and subsequently saturated from the soil layer boundary.

The sand for both CoS samples (one for the full model tests and one for the PIV test) was dry pluviated and vacuum levelled at $140 \mathrm{~mm}$ above the base of the strongbox including a coarser sand filter layer. Once the sand layer was fully saturated from the bottom, a clay layer with an approximate thickness of $20 \mathrm{~mm}$ was placed manually on top of the saturated sand. A similar total sample height of at least four times the skirt length for each sample was targeted to minimise boundary effects (Tran and Randolph 2008). The sand unit weight was determined from weight and volume measurements. The relative densities were $D_{r}=83 \pm 2 \%$.

Under consideration of scaling laws governing suction caisson response, the viscosity $\eta$ of the pore fluid of the sand was increased from approximately $\eta_{w}=1 \mathrm{cSt}$ for water to a target value of $\eta=100 \mathrm{cSt}$ (Taylor 2011). Hereby an effective permeability of the soil sample - i.e. $k_{f} \approx 1 \cdot 10^{-4} \mathrm{~m} / \mathrm{s}-$ at $100 g$ is targeted, which is representative of typical North Sea sands (Tan and Scott 1985). The viscosity was increased through the addition of methyl cellulose ether (DOW 2002). The targeted pore fluid viscosity was confirmed by measurements. The clay layer was water saturated. 


\section{Sample characterisation}

CPTs were performed before and after the suction caisson test at $100 \mathrm{~g}$. The utilised cone penetrometer has a diameter of $D_{c p t}=7 \mathrm{~mm}$ and was penetrated at a velocity of $v_{c p t}=1 \mathrm{~mm} / \mathrm{s}$, which is expected to result in drained conditions in sand (Finnie and Randolph 1994). The results shown in Figure 1 confirm similarity between and within each soil sample.

T-bar test were conducted in the clay immediately after consolidation at $1 g$ as well as before and after the suction caisson tests at $100 \mathrm{~g}$. The miniature penetrometer had a width of $w_{T b a r}=20 \mathrm{~mm}$, a plastic shear pin diameter of $D_{\text {Tbar }}=5 \mathrm{~mm}$ and a shaft diameter of $D_{\text {Tbar }, s}=6.3 \mathrm{~mm}$. The device was penetrated at $v_{T b a r}=1 \mathrm{~mm} / \mathrm{s}$, which is expected to result in undrained conditions in clay (Finnie and Randolph 1994). A T-bar factor of $N_{c, \text { Tbar }}=10.5$ (Low et al. 2010) was assumed to obtain the undrained shear strength profiles of the clay layer presented in Figure 2.

The equation given in Ladd et al. (1977) is utilised to predict the undrained shear strength $s_{u}=\sigma_{v}^{\prime}\left(s_{u} / \sigma_{v}^{\prime}\right)_{N C} O C R^{\Lambda}$, with $\Lambda=(\lambda-\kappa) / \lambda$. The normally consolidated undrained shear strength ratio $\left(s_{u} / \sigma_{v}^{\prime}\right)_{N C}$ ranges between 0.15 and 0.19 for kaolin clay (Lehane et al. 2009; Schofield and Wroth 1968), $\left(s_{u} / \sigma_{v}^{\prime}\right)_{N C}=0.19$ is assumed here. The undrained shear strength profiles, calculated with and without consideration of the sand top layer and assuming effective unit weights of $\gamma_{\text {sand }}^{\prime}=10.5 \mathrm{kN} / \mathrm{m}^{3}$ and $\gamma_{\text {clay }}^{\prime}=7.1 \mathrm{kN} / \mathrm{m}^{3}$, are included in Figure 2. Also included are the profiles from comparable tests calculated with the values given in Ragni et al. (2019) and Zhu et al. (2018b).

The results presented in Figure 2 show similarity to the predictions, which do not account for shallow penetration depth effects. The T-bar profiles also confirm undrained shear strength profiles between that of Ragni et al. (2019) and Zhu et al. (2018b), as targeted.

\section{Caisson model, test arrangement and instrumentation}

The full-model tests were performed with the same centrifuge arrangement as utilised by Stapelfeldt et al. (2020). The anodised aluminium model caisson had a diameter of $D=80 \mathrm{~mm}$ and a skirt length of $L=40 \mathrm{~mm}$, which when tested at $100 \mathrm{~g}$ represents a diameter $D=8 \mathrm{~m}$ and a skirt length of $L=4 \mathrm{~m}$ in prototype scale. In addition to this caisson with an aspect ratio $L / D=0.5$ a 
second caisson with the same diameter but an aspect ratio $L / D=1$ was also used in SoC. The skirt wall thickness was $t=0.5 \mathrm{~mm}$, which corresponds to a prototype wall thickness of $t=50 \mathrm{~mm}$. This yields a ratio of $D / t=160$ for these two model caissons.

For the PIV tests, a half-model caisson was manufactured, which had a diameter of $D=80 \mathrm{~mm}$ and a skirt length of $L=40 \mathrm{~mm}$. The wall thickness of this suction caisson is $t=2 \mathrm{~mm}$ for practical reasons (see also Ragni et al. (2018) and Ragni et al. (2019)). In order to facilitate comparison between half-model PIV tests and full-model caisson tests, an additional full-model caisson with a diameter of $D=80 \mathrm{~mm}$ and a skirt length of $L=40 \mathrm{~mm}$, but a wall thickness of $t=2 \mathrm{~mm}$ was manufactured, i.e. $D / t=40$.

Each caisson was equipped with two total pressure transducers (TTP) - one at the lid invert and another one at the top of the lid - and a pore pressure transducer (PPT) at the lid invert. The sensor arrangement is detailed in Bienen et al. (2018a) and Stapelfeldt et al. (2020). The caisson models were connected to a load cell with a maximum capacity of $3 \mathrm{kN}$ by means of a rigid rod. This assembly was carried by an actuator, which was mounted on top of the strongbox. The three way valve on the caisson lid was operated by an electric winch and was able to vent to ambient, to connect the caisson to the syringe pump (House 2002) and to be sealed. The water table was at least $100 \mathrm{~mm}$ above the soil surface to ensure that the model caisson including the three way valve were submerged to minimise changes in buoyancy during the installation. The self-weight and the cyclic loading of the model caisson were applied with the actuator, which was controlled through a feedback loop from the load cell. The displacement of the caisson was recorded by means of a linear displacement transducer (LDT).

The half-model caisson test required a set-up that allowed the self-weight and suction installation to be similar to the installations conduced with full-model-test. The PIV tests were performed with the testing arrangement developed by Ragni et al. (2018) and Ragni et al. (2019). The half-model is tested against a window to enable photographs from the outside. The interface between the model caisson and the perspex window was sealed with a combination of a soft foam seal and a rubber seal at the skirt tips, which was lubricated with petroleum jelly. Two five megapixel machine vision 
cameras captured images through the perspex window. The master-camera-equipped with an $8 \mathrm{~mm}$ lens - provided an overview of the entire window, while the follower-camera had a $43 \mathrm{~mm}$ lens providing a micro view of the suction caisson and a close range of the surrounding soil. This set-up yields an approximately 20 times increased resolution in this area. Both cameras were operated in sync at a frequency of two images per second during the suction caisson installation resulting in at least 20 images per millimetre of caisson penetration. Two LED-light panels ensured uniform illumination of the perspex window (Teng et al. 2017; Ragni et al. 2019). The PIV post-analysis follows Ragni et al. (2018) and Ragni et al. (2019).

\section{Testing nomenclature}

Table 3 summarises the caisson dimensions, applied vertical stress (self-weight) and pumping flow rate and applied cyclic load case of all 16 suction caisson tests. The tests were named as follows:

- The letters SoC and CoS indicate the stratification.

- The second number indicates the aspect ratio of the model suction caisson.

- A number letter combination indicates the installation method: $\mathrm{J}=$ jacked installation, $\mathrm{SI}=$ suction installation and $\mathrm{s}=$ slow and $\mathrm{f}=$ fast indicate variations of the pumping flow rate. The number represents the vertical load that was maintained during the installation of the model caisson. Tests with a displacement controlled self-weight installation are indicated by the letters DC instead of a number.

- The last number indicates the cyclic loading case. The half-model caisson tests are identified by the letters PIV instead of a load case (LC).

\section{Testing procedure}

Each test listed in Table 3 was performed in a different location. 


\section{Suction caisson installation}

The suction caisson installation for both, the full- and half-model caisson tests, was performed as follows:

(1) The caisson was suspended just above the soil surface until the centrifuge had reached the target acceleration to allow installation at stress levels representative of prototype conditions.

(2) The self-weight penetration was performed under load control at a constant loading rate of $1 \mathrm{~N} / \mathrm{s}$ in model scale. The three way valve vented to ambient until the self-weight penetration completed. A low self-weight was applied in SoC to achieve self-weight penetration prior to peak resistance in the sand layer in order to investigate onerous conditions for suction caisson installation. In $\mathrm{CoS}$, self-weight under realistic loads was assumed to penetrate the skirts to the underlying sand layer. The thick-walled full- and half-model caissons were penetrated in displacement control to comparable depths, which attracted higher loads. This self-weight was maintained through load control during the suction installation.

(3) Once the self-weight penetration stopped, the valve was switched to achieve a hydraulic connection between the caisson internal and the syringe pump without stopping the centrifuge. A constant pumping flow rate was applied, which was maintained until the caisson penetration stopped.

(4) The in-flight suction caisson installation was completed by sealing the valve without stopping the centrifuge.

Table 3 details the self-weight and pumping flow rate applied in each test.

\section{Loading of the model caissons}

The cyclic loading histories applied in this series of tests were selected to represent loading on a windward caisson of an $8 \mathrm{MW}$ suction caisson jacket supported OWT in approximately $40 \mathrm{~m}$ of water, and to facilitate comparison to previous tests performed in uniform sand. LC 10 featured the same cyclic loading history applied in previous tests performed in Baskarp sand (Bienen et al. 2018a; Bienen et al. 2018b) and fine silica sand (Stapelfeldt et al. 2020). LC 20 and 30 feature the 
same average load, but the cyclic loading amplitude was reduced by $25 \%$ and $50 \%$. The average load was shifted further into compression in LC 11 and 21 compared to the related LC 10 and 20, respectively. LC 11 in this study corresponds to LC 9 in Bienen et al. (2018a) and Bienen et al. (2018b). Without stoppage of the centrifuge to retain the soil stress state resulting from the suction installation, loading was applied to the suction caisson as follows:

(1) A waiting period was maintained to ensure that the suction pressure inside the caisson dissipated.

(2) The self-weight was increased to $V=585 \mathrm{~N}$ in model scale $(V / A=116 \mathrm{kPa})$. This represented the full self-weight of the jacket and the superstructure of the OWT - including tower, nacelle and rotor - applied to the caisson. This vertical load was maintained until the excess pore pressure at the lid invert dissipated and no further settlements were observed.

(3) The vertical load was reduced to the average vertical load given in Table 4. This represents the average vertical load assumed at the windward caisson of a suction caisson jacket.

(4) The average vertical load was maintained throughout the entire cyclic loading test. The cyclic loads were applied in packages of four sequences, each with a constant cyclic amplitude. The respective load amplitudes and the number of cycles per sequence are shown in Table 4. At least six load packages, i.e. a minimum of $n=6666$ load cycles, were applied in each test (Table 4).

(5) Following cyclic loading, the average load was maintained until the pore pressures reached the hydrostatic pressure. Displacement controlled extraction commenced. The three-wayvalve vented to ambient to ensure drained conditions at an uplift rate of $\dot{z}_{\text {ext }}=-0.001 \mathrm{~mm} / \mathrm{s}$. The caisson was then sealed again for rapid extraction, which was conducted at an uplift rate of $\dot{z}_{\text {ext }}=-0.1 \mathrm{~mm} / \mathrm{s}$.

The cyclic loads were applied at a loading frequency of $f=0.5 \mathrm{~Hz}$ and with regular sinusoidal amplitude. Loading due to wind, waves and current in a natural environment is expected to be highly irregular. However, the regular loading scheme was conceived to represent realistic drainage 
conditions in a reproducible manner. In addition this approach facilitates the evaluation of each LSQ and comparison between tests.

\section{RESULTS AND DISCUSSION}

The experimental results are presented in non-dimensional form, unless stated otherwise. Positive values indicate compression and downward displacements, whereas negative values represent tension and upward displacements.

\section{Sand over clay}

\section{Suction caisson installation}

Suction caisson installation in the SoC profile was unproblematic as expected, even with low self-weight of $V_{s w}=100 \mathrm{~N}$ in model scale or $(V / A)_{s w}=20 \mathrm{kPa}$ and a minimum model pumping flow rate of $q=196.4 \mathrm{~mm}^{2} / \mathrm{s}$ due to the low tip resistance, which was estimated at $R_{T} \approx 9 \mathrm{kPa}$ (Houlsby and Byrne 2005a; Ragni et al. 2020). Figure 3 shows that the selected self-weight resulted in penetration depths within the sand layer, as intended. The thick-walled caissons in tests SoC-0.5DCSI-20 and SoC-0.5-DCSI-PIV, of course, attracted higher loads for a self-weight penetration to approximately half of the sand layer. A vertical stress of $(V / A)_{s w}=30 \mathrm{kPa}$ in test SoC-1.0150SI-21, however, exceeded the capacity of the sand layer and resulted in rapid penetration into the underlying clay layer. The suction installation phase was unproblematic in all tests. Each suction caisson installed in SoC reached full penetration $(z / L \approx 1)$ in this study. This also holds for the results obtained from tests utilising the $L / D=1$ model caisson, which are normalised by $L_{80}=80 \mathrm{~mm}$ and $L_{40}=40 \mathrm{~mm}$, respectively, to facilitate comparison between the tests.

Figure 4 shows the applied installation pressure $(V / A)+s$, which corresponds to the cone tip resistance profile shown in Figure 1. The nature of the cone tip resistance profile, with a nose in the sand layer followed by a reduction in resistance, carries the risk of rapid penetration, which occurred in tests SoC-0.5-DCSI-20 and SoC-0.5-DCSI-PIV due to the increased self-weight (Table 3) upon commencement of suction.

Figure 4 further compares the penetration resistance profiles in SoC during suction installation with jacked installation, and with suction installation in a uniform sand profile. The penetration 
resistance in SoC is significantly lower compared with the installation of the same model caisson in sand, requiring lower suction, and the applied suction also reduces the penetration resistance compared to a jacked installation, as expected. This is consistent with predictions (Houlsby and Byrne 2005b; Houlsby and Byrne 2005a).

Normalised resultant displacement contours were obtained from PIV post-analyses as detailed in Ragni et al. (2018). The results presented in Figure 5a provide further insights, including soil plug heave developing in the early stages of suction installation, which remained approximately constant until the end of the suction installation (Figure 5a and 5b). However, the loosening was only temporary. The soil plug was compressed upon lid touch-down due to the vertical load and the ongoing evacuation of fluid from the caisson until the pumping system was stopped shortly after lid touch-down (Figure 5c). These results suggest that soil plug heave is reversible in SoC profiles.

\section{Tensile limiting capacities}

The extraction test results presented in Figure 6a show drained extraction capacities of $V / A \approx$ $25 \mathrm{kPa}$ for an aspect ratio of $L / D=0.5$ and $V / A \approx 65 \mathrm{kPa}$ for an aspect ratio of $L / D=1$, which is consistent with predictions (Houlsby and Byrne 2005a) obtained using the soil parameters given in Table 1 and 2 and an external and internal friction coefficient $(K \tan (\delta))_{o}=(K \tan (\delta))_{i}=0.15$ Stapelfeldt et al. (2020). The adhesion factors $\alpha_{o}=\alpha_{i}=0.4$ were obtained from cyclic T-bar tests. An uplift displacement of $z / L=0.006$ was required to completely mobilise the drained extraction capacity in SoC, which is larger than in uniform sand profiles (Bienen et al. 2018a; Stapelfeldt et al. 2020).

As the rapid extraction test SoC-0.5-125SI-20 and test SoC-0.5-150J-21, which was performed following drained extraction, show similar results (Figure 6b), the preceding drained extraction is deemed not to affect the capacity mobilised in subsequent rapid extraction.

Figure $6 \mathrm{~b}$ shows capacities and mobilisation distances in response to rapid extraction, in $\mathrm{SoC}$, which are similar to those in uniform sand as cavitation limits the uplift capacity. The caissons in tests SoC-1.0-125SI-20 and SoC-1.0-150SI-21 have larger capacity due to the longer skirts. However, the cavitation limit is similar, because the sum of the atmospheric and the hydrostatic 
pressure at the soil sample surface was similar. The undrained resistance is maintained until approximately $\Delta z / L \approx 0.4$ to $\Delta z / L \approx 0.7$.

Test SoC-0.5-DCSI-20 conducted with the thick-walled model caisson reached only $\approx 50 \%$ of the extraction capacity measured in tests performed with the thin-walled model caissons. The internal suction pressure does not exceed the atmospheric pressure and is therefore not visible in Figure 6b. This extraction test was affected by the previously applied cyclic loading sequences.

\section{Response to vertical cyclic loading}

Significance of the suction installation history LSQ 1 was the same in LC 20 and 30 and results in similar response despite different installation histories as shown in the enlarged section in Figure 7 (noting different vertical axis scales). LC 10 yields increased displacement amplitudes resulting from a reduced consolidation period prior to the cyclic loading, which is discussed in the following section. An effect of the installation process is therefore not found. This is consistent with the re-compression of the soil plug due to lid touch-down, which has been observed in the half-model caisson tests.

Load transfer mechanisms in sand over clay The results of test SoC-0.5-125SI-20 presented in Figure 7 show almost elastic behaviour with minor net uplift during LSQ 1 and 2. Figure 8a reveals that the response at the lid invert is undrained in each LSQ of every load package as the total stress at the lid invert is fully carried by the excess pore pressure, i. e. $\sigma=\Delta u$. This behaviour is representative for all tests conducted in SoC profiles. Figure 8 a further provides an indication of the changing share of skirt and lid contribution in transferring the applied load.

Figure $8 \mathrm{~b}$ shows the applied stress $V / A$ and the pore pressure $\Delta u$ transferred through the lid invert. The difference is carried by the soil-skirt interaction. This indicates that the skirt resistance is not fully mobilised, despite the fact that the peak stresses of LSQ 2 exceed the drained extraction capacity in tension $(V / A)_{S} \approx 25 \mathrm{kPa}$ and similarly the drained capacity in compression - i.e. the combined skirt and tip resistance of $(V / A)_{S}+(V / A)_{T} \approx 25+9 \approx 34 \mathrm{kPa}$. The tip resistance $V_{T}=\left(\gamma^{\prime} L N_{q}+s_{u} N_{c}\right)(\pi D t)$ (Houlsby and Byrne 2005a) was calculated assuming $N_{q}=1, N_{c}=10.5$ 
and the values given in Figure 2 and Table 2. The pore pressures at the lid invert cycle with the applied load so that the degree of mobilisation of the skirt (and tip, in compression) resistance remains constantly below 60\% in LSQ 1 and below 80\% in LSQ 2.

The skirt resistance is fully mobilised when the suction caisson is subjected to larger cyclic loads in LSQ 3 and LSQ 4 in test SoC-0.5-125SI-20. This results in an increasing displacement amplitude shown in Figure 7. The stresses transferred through the lid invert gradually increase with each compressive cycle of LSQ 3 and LSQ 4 (Figure 8b). This indicates that the share of vertical load transferred by the lid increases. Although net accumulation of excess pore pressure exists during these loading sequences, it dissipates during the following LSQ 1. This behaviour repeats with each loading package. This indicates that the soil recovers strength and skirt resistance is regained during low amplitude cyclic loading.

Loading as per LC 20 yields maximum displacement amplitudes of $\Delta z / L \approx 0.005$ in LSQ 3 and $\Delta z / L \approx 0.01$ in LSQ 4. Minor net uplift emerges, but the results presented in Figure 7 show that the vertical space between the hysteresis loops decreases after each load package - i. e. the net vertical displacement plateaus after several thousand load cycles.

The caisson displacement is governed by the soil permeability in uniform sand (Bienen et al. 2018b; Stapelfeldt et al. 2020). Since the sand plug is hydraulically encapsulated from ambient through the clay layer in SoC, undrained response and therefore a smaller displacement amplitude is likely. The dimensionless displacement rate $v^{\prime}=(\Delta \dot{z} L) / c_{v}$ (Finnie and Randolph 1994) can be estimated with the relative displacement rate $\Delta \dot{z}=2 \Delta z f$, the drainage path equalling the skirt length $L$ embedded in clay, and the coefficient of consolidation $c_{v}$ given in Table 2. A value of $v^{\prime}>30$, as in LSQ 3 and LSQ 4, indicates undrained behaviour. Furthermore, the tip resistance in clay is relatively low compared to sand. Consequently, the suction caisson responds with similar stiffness in compression and tension, which is different to uniform sand profiles where an increased stiffness, resulting from higher tip resistance, is present in compression. Hence, test SoC-0.5-125SI-20 shows that the undrained response to vertical loading and the soft tip response in SoC profiles leads to moderate net displacements. This mechanism is believed to be beneficial 
considering serviceability criteria in SoC.

The vertical loading amplitudes of LC 10 in LSQ 2, 3, and 4 are $25 \%$ larger compared to LC 20 (Table 4) and the consolidation time following installation was substantially shorter in test SoC0.5-350J-10 compared to test SoC-0.5-125SI-20. This resulted in significantly larger displacement amplitudes and net settlements in the short term (Figure 7), with tensile loads being transferred completely through suction pressure at the lid invert. However, the maximum displacement amplitudes and the rate of net settlement gradually decrease (Figure 9). The resulting long term displacement amplitudes in LC 10 appear to be proportional to the response during test SoC-0.5-125SI-20 and also plateaus in test SoC-0.5-350J-10 as the soil recovers strength.

Influence of the skirt wall thickness The comparison of the response of a thin- and a thick-walled model caisson to cyclic loading as per LC 20 is presented in Figure 10. The short term response of test SoC-0.5-DCSI-20 shows considerably increased vertical displacement amplitudes and net uplift. However, the long term response is characterised by a gradually increasing stiffness, which eventually leads to considerably reduced relative vertical displacements in each cycle compared to the results of test SoC-0.5-125SI-20 (Figure 10). The settlements measured during the test performed with the thick-walled model caisson contrast the net uplift observed in the thin-walled model caisson test.

Influence of average stress and cyclic loading amplitude Long-term net settlements instead of net uplift in test SoC-0.5-350J-10 is believed to result from the increased loading amplitude and therefore from the larger maximum compressive loads. The comparison of the displacement response between LC 20 and 30 (Figure 7) shows that reduced cyclic loading amplitudes limit the peak displacements while the overall uplift trend at a decreasing rate is similar. This observation is consistent, because Figures $8 \mathrm{~b}$ and $11 \mathrm{~b}$ reveal similarity between the underlying load transfer mechanisms, which governs the response to vertical cyclic loading in tests SoC-0.5-125SI-20 and SoC-0.5-100SIs-30.

A shift of the average vertical stress $(V / A)_{\text {ave }}$ further into compression changes the response 
to cyclic loading, even if similar excursion into tension are reached in LSQ 2, 3, and 4. LSQ 1 of LC 21 does not include excursions into tension. The results show that purely compressive cyclic loading in LSQ 1 yields settlements (Figures 12 and 13), as expected. Figure 13 also reveals that LC 21 results in larger relative vertical displacement amplitudes compared to LC 20, which is consistent because larger cyclic loading amplitudes are required to reach the same tensile peak load starting from an increased compressive average load. Furthermore, test SoC-0.5-150J-21 visualises the occurrence of net settlement in response to load sequences that feature significant excursions into tension.

Figure $8 \mathrm{~b}$ and 12 show that compressive loads are transferred by the skirt friction, tip resistance and the lid similarly in LC 20 and LC 21. Figure 12 shows that the skirt and tip resistance are arguably fully mobilised in LC 21 as significant net settlements result (Figure 13) instead of net uplift, which is present in test SoC-0.5-125SI-20.

The transfer mechanisms in tension differs: Tensile loads are completely transferred through suction pressure at the lid invert in LC 21 (Figure 12). Tensile loads are in contrast carried by the skirt friction and suction pressure in test SoC-0.5-125SI-20 (Figure 8b). Excess pore pressures, which are present in compression, dissipate before tensile loading commences at an increased average vertical stress (LC 21). Internal suction pressure therefore develops immediately and provides sufficient resistance. Excess pore pressures only partially dissipate before tensile loading is reached, if low compressive loads are present (LC 20). Hence, internal suction is mobilised later in this case and a portion of the tensile load is transferred by the skirt resistance. Based on the investigated load cases, it is concluded that the average compressive load determines whether cyclic loading with similar excursions into tension leads to net uplift or net settlement.

Influence of the caisson aspect ratio The two tests that were performed with a model caisson featuring an aspect ratio of $L / D=1$ show a significantly stiffer response to cyclic loading (LC 20 and 21) compared to the tests performed with the $L / D=0.5$ model caisson (Figure 13). Due to the increased skirt length, the applied loads in LC 20 do not exceed the measured skirt resistance 
of $(V / A)_{S} \approx 65 \mathrm{kPa}$ in tension and the sum of the skirt friction and the tip resistance $(V / A)_{S+T} \approx$ $74 \mathrm{kPa}$ in compression. The tip resistance $(V / A)_{T}=9 \mathrm{kPa}$ was calculated using Houlsby and Byrne (2005a) as detailed above. Figure 14a indeed shows that the skirt and the tip carry most of the vertical cyclic load applied to the caisson in test SoC-1.0-150SI-20. Thus, significantly lower excess pore pressures are recorded at the lid invert compared to the test results for a caisson with an aspect ratio of $L / D=0.5$ (Figure 8).

Similar to the the two previously discussed tests conducted with the $L / D=0.5$ model caisson, the development of suction pressure at the lid invert during unloading from significantly compressive loads applied in LC 21, which cycle with the applied load (Figure 14b), consistently provides additional resistance against uplift. Therefore, it is expected to limit the resulting displacements. The general trend of increased average compressive stresses shifting the response from net uplift to net settlement occurred in the tests for both aspect ratios. The increased skirt length provides additional resistance and stiffness in compression compared to the $L / D=0.5$ model caisson, which substantially reduces the vertical displacement amplitudes (Figure 13).

\section{Clay over sand}

\section{Suction caisson installation}

The self-weight installation resulted in skirt penetration depth of at least $z / L=0.5$ (Figure 15). Hence, the skirt tips were embedded in the underlying sand layer at the commencement of suction installation. Thus, the clay prevented a hydraulic connection between the sand and the syringe pump.

The results presented in Figure 15 show that the model caisson reached a total penetration depth of $z / L>0.95$ in the majority of the tests. Assuming even distribution of soil flow around the penetrating skirt during self-weight installation (achieved penetration measured) and inward flow during suction installation (Ragni et al. 2018; Ragni et al. 2020), the soil plug heave due to the displaced volume can be calculated. Therefore, a penetration depth of $z / L>0.98$ on average for $t=0.5 \mathrm{~mm}$ and $z / L>0.92$ for $t=2 \mathrm{~mm}$ implies full skirt penetration. A distinct change in gradient at the end of the curves presented in Figure 16 indicates contact between the lid and the 
soil plug, with the difference between calculated and achieved (Figure 15) penetration implying soil plug heave.

Senders and Randolph (2007) and Ragni et al. (2020) pointed out that clay plug uplift is required to transfer suction pressure to initiate seepage flow and hence reduce skirt tip resistance in the underlying sand. The clay plug uplift resistance, which is composed of plug self-weight and internal skirt resistance, is estimated to be $(V / A)_{c p} \leq 15 \mathrm{kPa}$. This value is exceeded by the suction pressure applied in addition to the self-weight stress (Figure 16). Consequently, clay plug uplift is believed to have occurred in each test performed in this series of centrifuge tests. The results of the PIV post-analyses presented in Figure 17 confirm clay plug uplift as the occurrence of a distinct gap is visible in Figure 17c. Furthermore, the history of the self-weight stress and the applied suction pressure presented in Figure 16 show that the gradient of the curves representing the installation of thin-walled model suction caissons in $\mathrm{CoS}$ aligns with test results found in test conducted in homogeneous sand (Stapelfeldt et al. 2020). This reinforces the observation of the seepage induced reduction of the skirt tip resistance in the underlying sand.

The displacement controlled self-weight penetration of the thick-walled model caissons yield vertical stresses of $V / A \approx 346 \mathrm{kPa}$ in test CoS-0.5-DCSI-10 and $V / A \approx 254 \mathrm{kPa}$ in test CoS-0.5DCSI-PIV (Figure 16). The estimated jacked penetration resistance at $z / L=0.65$ is $V / A=259 \mathrm{kPa}$ (Houlsby and Byrne 2005b). Assuming no seepage induced reduction of the tip resistance and utilising (Houlsby and Byrne 2005b), yields the requirement of a suction pressure of $s_{\text {req }}=169 \mathrm{kPa}$ in order to achieve full penetration of the thick-walled model caisson. Thus, a thick-walled model caisson installation would result in premature refusal due to the occurrence of cavitation. However, Figures 15 and 16 show that considerably less suction is required in order to achieve a penetration depth of $\Delta z / L>0.9$. This is feasible because of the presence of clay plug uplift induced seepage flow which reduces the skirt tip resistance significantly - even for thick-walled model caissons (Tran et al. 2004). These results underpin the findings derived from half-model caisson installation test and PIV post-analyses discussed above and in Ragni et al. (2020).

The maximum plug heave and resulting gap at the layer boundary is visualised in Figure 17c 
at a relative skirt penetration depth of $\Delta z / L=0.9$. The course of the caisson penetration of tests CoS-0.5-350SI-11 and CoS-0.5-DCSI-PIV features a clay plug drop close to the end of skirt penetration, which is visible in Figure 16. This event indicates the sudden equalisation of the differential pressure between the top and bottom of the clay plug - i.e. a vertical fluid channel between clay layer and the skirt opens. The overall caisson internal suction pressure is maintained due to the drainage regime, which is present in the underlying sand. The results of the PIV postanalysis shown in Figure 17d reveal that the establishment of a flow channel is accompanied by a clay plug drop closing the gap shown in Figure 17c.

The results presented in Figures 15 to 17 confirm the feasibility of the suction caisson installation in $\mathrm{CoS}$ profiles at moderate and high pumping flow rates with similar governing mechanisms as revealed for the first time in Ragni et al. (2020), despite differences in clay layer strength and suction caisson aspect ratio. In each test discussed here, suction caisson installation in CoS resulted in less plug heave compared with installation in uniform sand (Bienen et al. 2018a; Ragni et al. 2019; Stapelfeldt et al. 2020). This is consistent with the results presented in Ragni et al. (2020). This includes test CoS-0.5-350SIf-10, which was installed at the maximum possible pumping flow rate and the maximum suction pressure measured at the lid invert within this series of tests. The achieved penetration depth of this test is similar to all others conducted with the thin-walled model caisson.

However, the actual extent of the clay and sand plug heave remains invisible in the full model tests and the discussed PIV post-analyses are based on experiments conducted with thick-walled model caissons. Consequently, the role of the skirt wall thickness will be further discussed under consideration of possible consequences on the in-service performance in the following sections.

\section{Tensile limiting capacities}

Figure 18a shows that a maximum resistance of $V / A \approx 10 \mathrm{kPa}$ was measured during the drained extraction test performed in the CoS profile. Hence, the drained uplift resistance is smaller compared to uniform sand profiles (Bienen et al. 2018a; Stapelfeldt et al. 2020). However, a skirt resistance within the magnitude of the $V / A \approx 25 \mathrm{kPa}$ measured in SoC profiles is expected for the 
$L=40 \mathrm{~mm}$ model caisson, because the skirt is similarly embedded in $20 \mathrm{~mm}$ of clay and sand in SoC and CoS. However, the results presented in Figure 18a indicate a possible presence of flow channels, because areas of the skirt that are detached from the clay layer do not provide uplift resistance.

The results presented in Figure 18a also reveal a dependency between the uplift resistance and the cyclic loading history: A larger net uplift resulting from cyclic loading expectedly leads to a reduced uplift capacity due to a lower embedded depth $z / L$ in the beginning of the extraction. Tests CoS-0.5-350-SI-10 and CoS-0.5-350-SIf-10 have a similar cyclic loading history. However, the drained uplift capacity differs considerably. The only distinct difference between both test is an extended waiting period between the cyclic loading and the extraction of test CoS-0.5-350-SI-10.

The response to rapid uplift shown in Figure $18 \mathrm{~b}$ is more complex and depends on the behaviour of the clay plug. Two different possible mechanisms are identified to govern suction caisson extraction in a $\mathrm{CoS}$ profile:

(1) It is expected that the clay plug is lifted once the suction pressure at the lid invert exceeds its self-weight and suction pressure will be transferred into the underlying sand. The extraction resistance depends on the degree of drainage in the sand layer and is limited by cavitation. This case is believed to be present in test CoS-0.5-350SIf-10. The distinct change in gradient at $\Delta z / L \approx 0.05$ is thought to mark the beginning of the relative movement of the clay plug and therefore the start of the suction pressure transferral. The clay plug in test CoS-0.5350SIf-10 may have partially obstructed the sensor, resulting in high suction measured at the lid invert but a relatively low extraction resistance. The uplift capacity measured in this test is significantly smaller compared to tests conducted in uniform sand (Bienen et al. 2018a).

(2) If flow channels occur immediately, it is expected that only the drainage conditions of the underlying sand determine the extraction resistance resulting from rapid tensile loading. The results presented in Figure 19 reveal the actual presence of this mechanism during test CoS-0.5-DCSI-PIV. Minor clay plug uplift is visible in Figure 19a, which corresponds to 
$\Delta z / L \geq 0.05$, i. e. the state before the two curves relating to this test separate in Figure $18 \mathrm{~b}$. Significantly reduced clay plug displacements occur (Figure 19b). The internal suction pressures developed during test CoS-0.5-DCSI-PIV (Figure 18b) can be explained as the clay plug uplift is still present, but slower compared with the caisson upward movement despite the occurrence of flow channels. It is expected that the suction pressure eventually dissipates completely due to on going development of flow channels, which finally yields the clay plug drop that was observed by Ragni et al. (2020). However this state was not reached in this test, because it terminated before the maximum capacity was reached as the foam seal failed at $\Delta z / L \approx 0.2$.

Both cases demonstrate that the load transfer mechanisms in CoS profiles differ from those present during uplift of suction caisson foundations embedded in uniform sand (Bienen et al. 2018a) and are considerably more complex. Clay plug uplift and the resulting drainage conditions in the underlying sand layer critically influence the response.

\section{Response to vertical cyclic loading}

Significance of the suction installation history Figure 20 presents the response to vertical cyclic loading of two tests with different suction installation histories (Table 3) but identical LCs. The target tensile vertical load in test CoS-0.5-350SIf-10 was underachieved. However, both test show a similar response in compression and comparable net uplift development over five loading packages. No distinct difference was found between these two tests. Consequently, no evidence of a possible influence of the installation history on the vertical cyclic load transfer mechanisms was found in this study. This is consistent with the findings discussed above.

Load transfer mechanisms in clay over sand The results presented in Figure 21 show an almost elastic response to LSQ 1 of LC 10 , whereby the maximum targeted tensile load of $V / A \approx 8 \mathrm{kPa}$ is not expected to exceed the drained skirt resistance. The caisson responds with substantially increased displacement amplitudes in tension once the drained capacity is exceeded - especially in LSQ 3 and LSQ 4. The displacement amplitudes are approximately two times larger than in 
comparable tests conducted in uniform fine silica sand (Stapelfeldt et al. 2020). The pressure carried at the lid invert cycles with the vertical load (Figure 21a), which is also similar to the behaviour in sand. The history of the effective load further indicates significantly stiffer response in compression (Figure 21b). This is also consistent with the caisson response to similar test performed in sand (Stapelfeldt et al. 2020).

Figure 21 represents undrained behaviour at the lid invert in compression and tension as expected due to clay constituting the top of the soil plug. The drainage regime in the sand layer depends on the drainage path length and hence on the uplift of the clay plug and/or any flow channels developing along the skirt interface. The area covered by the hysteresis loops is larger in CoS than in sand, corresponding to a higher degree of drainage overall as already seen during the caisson extraction tests.

The reasonably stiff response to compressive loads is also influenced by the tip resistance. For instance, Figure 21 a shows that the tip carries approximately $50 \%$ of the applied compressive load during LSQ 3, which implies net uplift in each load package - especially from the second load package. Based on the presented results it is concluded that the mobilisation of the tip resistance in compression determines the net uplift response of a suction caisson foundation embedded in $\operatorname{CoS}$ when subjected to vertical cyclic loading.

Influence of the skirt wall thickness The results of the same loading history applied to the thinand thick-walled suction caissons are shown in Figure 22. While LC 10 results in net uplift after each loading package in both cases, substantially larger net uplift occurred in the test with the thick-walled caisson CoS-0.5-DCSI-10. Figure 22b reveals the influence of the thick skirt tips as a larger share of the applied compressive load is carried by the skirt compared to test CoS-0.5-350SI10 (Figure 21a), although the response to tensile loading is similar. Consequently, settlements in compression are limited in test CoS-0.5-DCSI-10 (Figure 22a) and net uplift emerges - especially after LSQ 4. However, the installation response is similar as the tip resistance is reduced due to the suction pressure induced seepage flow. The skirt wall thickness alters the suction caisson response 
to vertical cyclic loading as the $t=2 \mathrm{~mm}$ skirt wall thickness attracts considerably increased tip resistance compared to the model caisson with $t=0.5 \mathrm{~mm}$ skirt wall thickness.

Influence of average stress and cyclic loading amplitude The response to vertical cyclic loading presented in Figure 23 is significantly different in each of the four LCs, which differ in terms of average load and cyclic loading amplitude or both (Table 4). The results of (1) similar average stress, but different cyclic loading amplitude, (2) different average stress, but similar cyclic amplitude and (3) different average stress, but similar tensile load are discussed below:

(1) LC 10 and 20 have the same average compressive stress, but the amplitude of loading sequences 2,3 , and 4 is reduced by $25 \%$ in LC 20 . Figure 23 shows a significant increase of the net uplift due to the reduction of the loading amplitude - especially during LSQ 3 and LSQ 4. The magnitude of the upward displacement in a single cycle during LSQ 3 and LSQ 4 is comparable in both load cases. Furthermore, Figures 21a and 24 show a comparable development of suction pressure at the lid invert during tensile loading. This indicates the presence of a similar tensile load transfer mechanism characterised by a combination of skirt resistance and internal suction pressure, which is believed to be transferred through the clay plug into the underlying sand in both tests.

The suction pressure dissipates once the loading moves into compression and excess pore pressure develops. Figures 24 shows that the maximum excess pore pressure is lower in test CoS-0.5-350SI-20 compared to test CoS-0.5-350SI-10. Thus, a reduced share of the vertical load is transferred through the lid. Reduced cyclic amplitudes imply lower maximum compressive stresses and hence settlements, as expected. Since the overall response in compression is significantly stiffer than in tension, the reduction of the loading amplitude reinforces the imbalance of upward and downward displacement during cyclic loading, which yields increased net uplift as also discussed for sand in Bienen et al. (2018b).

(2) A shift of the average load into compression while maintaining the cyclic loading amplitude 
(LC 10 and LC 11) results in net settlement instead of net uplift, which is shown in Figure 23. Furthermore, the displacement amplitude measured in test CoS-0.5-350SI-11 is significantly smaller compared to test CoS-0.5-350SI-10. Figure 25a shows that suction pressure already develops during unloading from compression. This yields additional uplift resistance and is expected to reduce the respective displacement amplitude. Furthermore, Figure 25a shows compressive behaviour that is similar to the results of test CoS-0.5-350SI-20 presented in Figure 24 - i.e. the majority of the compressive load is carried by the skirt. Similar response was observed in uniform Baskarp sand (Bienen et al. 2018a; Bienen et al. 2018b).

The increased compressive average load also implies that tension is not applied before LSQ 3. This leads to the response illustrated in Figure 25b: almost elastic behaviour in LSQ 1, net settlements in LSQ 2 and LSQ 3, and zero net displacement in LSQ 4. The occurance of settlements despite excursions into tension in LSQ 3 and the absence of net uplift in LSQ 4 shown in Figure 25b are remarkable here. It indicates that tensile cyclic loading exceeding the drained extraction capacity can be withstood without resulting in net uplift. The comparison between the responses to loading of LC 10 and 11 consequently indicates that the average vertical stress, i. e. the compressive stress following an excursion into tension, determines the direction of net displacements in CoS profiles. This is similar to findings for suction caissons in sand (Bienen et al. 2018b).

(3) Results of tests with different average but similar tensile stresses (LC 20 and LC 21) provide the following insights: The higher average compressive stress in LC 21 leads to a significant change in displacement response compared to LC 20, which is shown in Figure 23. Net settlement instead of excessive net uplift was observed during test CoS-0.5-350SI-21, which is consistent with the previous results. The development of pore pressures and the share of load carried by the lid invert presented in Figure 26a is similar to the response to LC 11 shown in Figure 25a. This confirms that the average vertical stress indeed determines the overall response to vertical cyclic loading in $\mathrm{CoS}$ profiles.

A more detailed evaluation of LSQ 3 provides the following insights: LC 21 al- 
ready featured excursions into tension that exceeded the drained extraction capacity from LSQ 2. Figure $26 \mathrm{~b}$ shows that net settlements were measured during LSQ 1 and LSQ 2 and net uplift was recorded during LSQ 3 and LSQ 4, which result in marginal net vertical displacements overall. This comparison between test CoS-0.5-350-SI-20 and CoS-0.5-350SI-21 demonstrates a suction caisson foundation in $\mathrm{CoS}$ can withstand similar tensile loads without considerable net displacements, if a sufficiently large compressive load follows the tensile load.

\section{CONCLUDING REMARKS}

Investigation of suction caisson installation in layered soils - sand over clay and clay over sand - and performance under subsequent vertical cyclic loading into tension through centrifuge tests support the following findings: Suction caisson installation is proven to be feasible in sand over clay and clay over sand. Due to seepage induced reduction of skirt tip resistance, suction caisson installation is insensitive to the skirt thickness. This allows further insights to be revealed through centrifuge tests with particle image velocimetry post-analysis. The same does not hold for suction caisson response under vertical cyclic loading where the skirt tip is embedded in sand attracting high skirt tip resistance.

In sand over clay:

(1) The suction caisson installation is unproblematic as expected - even in stiff clay. Furthermore, no evidence of a permanent effect on the behaviour under vertical cyclic loading was found as the soil plug was shown to be compressed through lid contact.

(2) The skirt embedment into underlying low permeability clay encapsulates the internal sand plug and leads to predominately undrained behaviour in compression and tension. The relatively low tip resistance in clay balances the displacement response to cyclic loading around a compressive average load - including significant excursions into tension.

(3) The displacement amplitudes relate to the cyclic loading amplitude and the net displacement direction is governed by the average vertical stress. The model caissons in sand over 
clay withstood maximum tensile loads that significantly exceeded the drained capacity in numerous loading cycles without excessive net displacements.

(4) An increased aspect ratio - i.e. skirt length - leads to an overall stiffer response during cyclic vertical loading, as expected.

In clay over sand:

(1) Suction caisson installation is feasible with clay plug uplift transferring suction pressure to the underlying sand. This mechanism was visualised for the first time in Ragni et al. (2020), with clay layer thicknesses between $z / L=0.2$ and $z / L=0.6$. The induced seepage reduces the tip resistance and enables further penetration. A permanent effect of the installation on the response under vertical cyclic loading was not found.

(2) The response to tensile loading is complex. Clay plug uplift and the resulting suction pressure transferral into the underlying sand was identified to affect the extraction resistance and response to vertical cyclic loading. As in homogeneous sand, the resulting drainage regime crucially affects the response.

(3) The relatively large tip resistance in the underlying sand limits settlements. This favours net uplift in response to vertical cyclic loading (which is exacerbated with increasing skirt wall thickness). Consequently, sufficiently compressive average vertical stresses or limited excursions into tension are found to be required to limit net uplift.

Predictions of suction caisson response in layered soil should therefore account for the interplay between the soil stratification, the caisson dimensions (as a proxy for drainage path length) and cyclic loading characteristics. The complexity of this inter-relation, as discussed in this paper, requires further research in order to reach the formulation of a predictive method.

\section{DATA AVAILABILITY STATEMENT}

Some or all data, models, or code that support the findings of this study are available from the corresponding author upon reasonable request. 


\section{ACKNOWLEDGEMENTS}

We acknowledge the support from the Deutsche Forschungsgemeinschaft (DFG) for our research project GR 1024/26-2 Sauginstallation Maritimer Strukturen (SIMS). This work forms part of the activities of the Centre for Offshore Foundation Systems (COFS), which is currently supported as a Centre of Excellence by the Lloyd's Register Foundation. Lloyd's Register Foundation helps to protect life and property by supporting engineering-related education, public engagement and the application of research. This support is gratefully acknowledged.

\section{REFERENCES}

Al-Tabbaa, A. and Wood, D. M. (1987). "Some measurements of the permeability of kaolin." Géotechnique, 37(4), 499-514.

Bienen, B., Klinkvort, R. T., O’Loughlin, C. D., Zhu, F., and Byrne, B. W. (2018a). "Suction caissons in dense sand, part i: Installation, limiting capacity and drainage." Géotechnique, 68(11), 937-952.

Bienen, B., Klinkvort, R. T., O’Loughlin, C. D., Zhu, F., and Byrne, B. W. (2018b). "Suction caissons in dense sand, part ii: Vertical cyclic loading into tension." Géotechnique, 68(11), 953-967.

Broughton, P., Davies, R. L., and Jenkins, J. (2013). "The removal of the maureen steel gravity platform." Offshore Technology Conference, Offshore Technology Conference, 1-14.

Chow, S. H., O'Loughlin, C. D., Gaudin, C., and Lieng, J. T. (2018). "Drained monotonic and cyclic capacity of a dynamically installed plate anchor in sand." Ocean Engineering, 148, 588-601.

Colreavy, C., O'Loughlin, C. D., and Randolph, M. F. (2016). "Experience with a dual pore pressure element piezoball." International Journal of Physical Modelling in Geotechnics, 16(3), $101-118$.

Cotter, O. (2010). "Installation of suction caisson foundations for offshore renewable energy structures." Phd thesis, University of Oxford, Oxford.

DOW (2002). Methocel cellulose ethers: Technical handbook. United States of America.

Finnie, I. M. S. and Randolph, M. F. (1994). "Punch-through and liquefaction induced failure 
of shallow foundations on calcareous sediments." Seventh International Conference on the Behaviour of Offshore Structures, Vol. 1, United Kingdom, Pergamon, 217-230.

Houlsby, G. T. and Byrne, B. W. (2005a). "Design procedures for installation of suction caissons in clay and other materials." Proceedings of the Institution of Civil Engineers - Geotechnical Engineering, 158(2), 75-82.

Houlsby, G. T. and Byrne, B. W. (2005b). "Design procedures for installation of suction caissons in sand." Geotechnical Engineering, 158(3), 135-144.

House, A. R. (2002). "Suction caisson foundations for buoyant offshore facilities.” Phd thesis, The University of Western Australia, Perth.

Jeong, Y. H., Park, H. J., Kim, D. S., and Kim, J. H. (2018). "Cyclic behaviour of unit bucket for tripod foundation system under various loading characteristics via centrifuge." Physical Modelling In Geotechnics, Volume 1, CRC Press, [S.1.], 609-614.

Ladd, C. C., Foot, R., Ishihara, K., Schlosser, F., and Poulos, H. G. (1977). "Stress-deformation and strength characteristics." Proceedings of the 9th International Conference on Soil Mechanics and Foundation Engineering, Japanese Society of Soil Mechanics and Foundation Engineering, ed., 421-494.

Lehane, B. M. and Liu, Q. B. (2013). "Measurement of shearing characteristics of granular materials at low stress levels in a shear box." Geotechnical and Geological Engineering, 31(1), 329-336.

Lehane, B. M., O’Loughlin, C. D., Gaudin, C., and Randolph, M. F. (2009). "Rate effects on penetrometer resistance in kaolin.” Géotechnique, 59(1), 41-52.

Low, H. E., Lunne, T., Andersen, K. H., Sjursen, M. A., LI, X., Randolph, M. F., Andersen, K. H., Randolph, M. F., Andersen, K. H., and Randolph, M. F. (2010). "Estimation of intact and remoulded undrained shear strengths from penetration tests in soft clays." Géotechnique, 60(11), $843-859$.

Ragni, R., Bienen, B., O’Loughlin, C. D., Stanier, S. A., Cassidy, M. J., and Morgan, N. (2020). "Observations of the effects of a clay layer on suction bucket installation in sand." Journal of Geotechnical and Geoenvironmental Engineering, 146(5), 04020020. 
Ragni, R., Bienen, B., Stanier, S., O’Loughlin, C., and Cassidy, M. (2019). “Observations during suction bucket installation in sand." International Journal of Physical Modelling in Geotechnics, 1-49.

Ragni, R., Bienen, B., Stanier, S. A., Cassidy, M. J., and O’Loughlin, C. D. (2018). "Visualisation of mechanisms governing suction bucket installation in dense sand." Physical Modelling In Geotechnics, Volume 1, CRC Press, [S.1.], 651-565.

Raines, R. D., Ugaz, O., and Garnier, J. (2005). "Centrifuge modeling of suction piles in clay." Frontiers in offshore geotechnics, S. Gourvenec and M. Cassidy, eds., Balkema, Taylor \& Francis, London, 303-308.

Randolph, M. F. and Gaudin, C. (2017). "Genesis of the national geotechnical centrifuge facility a 30 year perspective..” Australian Geomechanics Journal, 52(2), 1-14.

Randolph, M. F., Jewell, R. J., Stone, K. J. L., and Brown, T. A. (1991). "Establishing a new centrifuge facility." Proc. International Conference Centrifuge 1991, H.-J. Ko and F. G. McLean, eds., Rotterdamm, Belkema, 3-9.

Schofield, A. N. and Wroth, P. (1968). Critical state soil mechanics. European civil engineering series. McGraw-Hill, London and New York.

Senders, M. and Randolph, M. F. (2007). "Theory for the installation of suction caissons in sand overlaid by clay." 6th International Conference on Offshore Site Investigation and Geotechnics, $429-438$.

Senpere, D. and Auvergne, G. A. (1982). "Suction anchor piles - a proven alternative to driving or drilling." Offshore Technology Conference, Vol. OTC 4206, 483-493.

Stanier, S. A., Blaber, J., Take, W. A., and White, D. J. (2016). "Improved image-based deformation measurement for geotechnical applications." Canadian Geotechnical Journal, 53(5), 727-739.

Stanier, S. A. and White, D. J. (2013). "Improved image-based deformation measurement in the centrifuge environment." Geotechnical Testing Journal, 36(6), 915-928.

Stapelfeldt, M., Bienen, B., and Grabe, J. (2020). "The influence of the drainage regime on the installation and the response to vertical cyclic loading of suction caissons in dense sand." Ocean 
Engineering, 215, 107105.

Tan, T.-S. and Scott, R. F. (1985). "Centrifuge scaling considerations for fluid-particle systems: Centrifuge scaling considerations for fluid-particle systems." Géotechnique, 35(4), 461-470.

Taylor, R. N. (2011). Geotechnical centrifuge technology. Taylor \& Francis, London.

Teng, Y., Stanier, S. A., and Gourvenec, S. M. (2017). "Synchronised multi-scale image analysis of soil deformations." International Journal of Physical Modelling in Geotechnics, 17(1), 53-71.

Tjelta, T. (2015). "The suction foundation technology." Frontiers in offshore geotechnics III, V. Meyer, ed., CRC Press/Balkema, Leiden, Netherlands, 85-93.

Tjelta, T. I., Guttormsen, T. R., and Hermstad, J. (1986). "Large-scale penetration test at a deepwater site." Offshore Technology Conference, Offshore Technology Conference, 201-212.

Tran, M. N. (2005). "Installation of suction caissons in dense sand and the influence of silt and cemented layers." Phd thesis, The University of Sydney, Sydney.

Tran, M. N. and Randolph, M. F. (2008). "Variation of suction pressure during caisson installation in sand." Géotechnique, 58(1), 1-11.

Tran, M. N., Randolph, M. F., and Airey, D. W. (2004). "Experimental Study of Suction Installation of Caissons in Dense Sand." Proceedings of the 23rd International Conference on Offshore Mechanics and Arctic Engineering - 2004, New York, NY, ASME, 105-112.

Tran, M. N., Randolph, M. F., and Airey, D. W. (2007). "Installation of suction caissons in sand with silt layers." Journal of Geotechnical and Geoenvironmental Engineering, 133(10), 1183-1191.

Watson, P. G., Gaudin, C., Senders, M., and Randolph, M. F. (2006). "Installation of suction caissons in layered soil." 6th International Conference on Physical Modelling in Geotechnics (ICPMG) // Physical Modelling in Geotechnics, Two Volume Set, C. W. W. Ng, Y. H. Wang, and L. M. Zhang, eds., Hoboken, CRC Press, 685-692.

Zhu, F., Bienen, B., O’Loughlin, C., Morgan, N., and Cassidy, M. J. (2018a). "The response of suction caissons to multidirectional lateral cyclic loading in sand over clay." Ocean Engineering, $170,43-54$.

Zhu, F., O’Loughlin, C. D., and Bienen, B. (2017). "Physical modelling of suction bucket installa- 
tion and response under long-term cyclic loading." Offshore site investigation and geotechnics, Society for Underwater Technology, ed., Society for Underwater Technology, London, UK, $524-531$.

Zhu, F., O’Loughlin, C. D., Bienen, B., Cassidy, M. J., and Morgan, N. (2018b). “The response of suction caissons to long-term lateral cyclic loading in single-layer and layered seabeds." Géotechnique, 68(8), 729-741.

Zografou, D., Gourvenec, S., and O’Loughlin, C. D. (2019). "Vertical cyclic loading response of shallow skirted foundation in soft normally consolidated clay." Canadian Geotechnical Journal, $56(4), 473-483$. 


\section{List of Tables}

1 Soil properties of fine silica sand. . . . . . . . . . . . . . . . 32

2 Soil properties of kaolin clay. . . . . . . . . . . . . . . . 33

3 Centrifuge testing programme. . . . . . . . . . . . 34

4 Load cases and specifications of the four respective cyclic loading sequences (LSQs). 35 
TABLE 1. Soil properties of fine silica sand.

\begin{tabular}{lll}
\hline \multicolumn{1}{c}{ Parameter } & \multicolumn{2}{c}{ Value } \\
\hline Grain density $\left(\mathrm{t} / \mathrm{m}^{3}\right)$ & $\rho_{s}$ & 2.67 \\
Mean grain size $(-)$ & $d_{50}$ & 0.18 \\
Min. void ratio (-) & $e_{\min }$ & 0.490 \\
Max. void ratio (-) & $e_{\max }$ & 0.784 \\
Peak friction angle $\left(^{\circ}\right)$ & $\varphi^{\prime}$ & 43.1 \\
Effective permeability $(\mathrm{m} / \mathrm{s})$ & $k_{f}$ & $\approx 1 \cdot 10^{-4}$ \\
\hline Source: Data from Tran $(2005)$; Lehane and Liu (2013); Chow et al. (2018).
\end{tabular}


TABLE 2. Soil properties of kaolin clay.

\begin{tabular}{lll}
\hline \multicolumn{1}{c}{ Parameter } & & Value \\
\hline Grain density $\left(\mathrm{t} / \mathrm{m}^{3}\right)$ & $\rho_{s}$ & 2.6 \\
Liquid limit $(\%)$ & $L L$ & 61 \\
Plastic limit (\%) & $P L$ & 27 \\
Peak friction angle $\left(^{\circ}\right)$ & $\varphi^{\prime}$ & 23 \\
Critical state friction coefficient & $M$ & 0.92 \\
Void ratio at CSL ${ }^{\mathrm{a}}(-)$ & $e_{c s}$ & 2.14 \\
Slope NCL (-) & $\lambda$ & 0.205 \\
Slope URL $(-)$ & $\kappa$ & 0.044 \\
Effective permeability (m/s) & $k_{f}$ & $\approx 1.7 \cdot 10^{-9}$ \\
Coefficient of consolidation ${ }^{\mathrm{b}}\left(\mathrm{m}^{2} / \mathrm{a}\right)$ & $c_{v}$ & 5.5 \\
\hline${ }^{\mathrm{a}} p^{\prime}=1 \mathrm{kPa}$ & & \\
${ }_{\mathrm{b}}$ estimated for stress level at skirt tip and $O C R=7.1$ \\
\hline Source: Data from Al-Tabbaa and Wood $(1987) ;$ Colreavy et al. (2016).
\end{tabular}


TABLE 3. Centrifuge testing programme.

\begin{tabular}{llcccc}
\hline Test No. & Test name & $\begin{array}{c}\text { Vertical stress } \\
V / A(\mathrm{kPa})\end{array}$ & $\begin{array}{c}\text { Pumping flow rate } \\
q\left(\mathrm{~mm}^{3} / \mathrm{s}\right)\end{array}$ & $\begin{array}{c}\text { Model dimensions } \\
D / L / t(\mathrm{~mm})\end{array}$ & Load case \\
\hline 1 & SoC-0.5-350J-10 & 70 & jacked installation & $80 / 40 / 0.5$ & 10 \\
2 & SoC-0.5-100SIs-30 & 20 & 196.4 & $80 / 40 / 0.5$ & 30 \\
3 & SoC-0.5-125SI-20 & 25 & 392.7 & $80 / 40 / 0.5$ & 20 \\
4 & SoC-0.5-150J-21 & 30 & jacked installation & $80 / 40 / 0.5$ & 21 \\
5 & SoC-1.0-125SI-20 & 25 & 392.7 & $80 / 80 / 0.5$ & 20 \\
6 & SoC-1.0-150SI-21 & 30 & 392.7 & $80 / 80 / 0.5$ & 21 \\
7 & SoC-0.5-DCSI-20 & 56 & 392.7 & $80 / 40 / 2.0$ & 20 \\
8 & SoC-0.5-DCSI-PIV & $24^{\mathrm{a}}$ & $196.4^{\mathrm{a}}$ & $80 / 40 / 2.0$ & PIV \\
\hline 9 & CoS-0.5-350SI-10 & 70 & 392.7 & $80 / 40 / 0.5$ & 10 \\
10 & CoS-0.5-350SI-20 & 70 & 392.7 & $80 / 40 / 0.5$ & 20 \\
11 & CoS-0.5-350SI-21 & 70 & 392.7 & $80 / 40 / 0.5$ & 21 \\
12 & CoS-0.5-350SIf-10 & 70 & 1963.5 & $80 / 40 / 0.5$ & 10 \\
13 & CoS-0.5-350SI-11 & 70 & 392.7 & $80 / 40 / 0.5$ & 11 \\
14 & CoS-0.5-DCSI-F & 70 & $392.7^{\mathrm{b}}$ & $80 / 40 / 0.5$ & - \\
15 & CoS-0.5-DCSI-10 & 346 & 392.7 & $80 / 40 / 2.0$ & 10 \\
16 & CoS-0.5-DCSI-PIV & $127^{\mathrm{a}}$ & $196.4^{\mathrm{a}}$ & $80 / 40 / 2.0$ & PIV \\
\hline
\end{tabular}

${ }^{\mathrm{a}}$ values apply to half model

$\mathrm{b}_{\text {test failed during suction installation }}$ 
TABLE 4. Load cases and specifications of the four respective cyclic loading sequences (LSQs).

\begin{tabular}{clcccc}
\hline Load case & Parameter & LSQ 1 & LSQ 2 & LSQ 3 & LSQ 4 \\
\hline \multirow{3}{*}{10} & Number of cycles $n$ & 1000 & 100 & 10 & 1 \\
& Cyclic load amplitude $V(\mathrm{~N})$ & $40 \pm 80$ & $40 \pm 200$ & $40 \pm 400$ & $40 \pm 600$ \\
& Cyclic stress amplitude $V / A(\mathrm{kPa})$ & $8 \pm 16$ & $8 \pm 40$ & $8 \pm 80$ & $8 \pm 120$ \\
\hline \multirow{3}{*}{11} & Number of cycles $n$ & 1000 & 100 & 10 & 1 \\
& Cyclic load amplitude $V(\mathrm{~N})$ & $300 \pm 80$ & $300 \pm 200$ & $300 \pm 400$ & $300 \pm 600$ \\
& Cyclic stress amplitude $V / A(\mathrm{kPa})$ & $60 \pm 16$ & $60 \pm 40$ & $60 \pm 80$ & $60 \pm 120$ \\
\hline \multirow{3}{*}{20} & Number of cycles $n$ & 1000 & 100 & 10 & 1 \\
& Cyclic load amplitude $V(\mathrm{~N})$ & $40 \pm 80$ & $40 \pm 150$ & $40 \pm 300$ & $40 \pm 450$ \\
& Cyclic stress amplitude $V / A(\mathrm{kPa})$ & $8 \pm 16$ & $8 \pm 30$ & $8 \pm 60$ & $8 \pm 90$ \\
\hline \multirow{3}{*}{21} & Number of cycles $n$ & 1000 & 100 & 10 & 1 \\
& Cyclic load amplitude $V(\mathrm{~N})$ & $160 \pm 120$ & $160 \pm 270$ & $160 \pm 420$ & $160 \pm 570$ \\
& Cyclic stress amplitude $V / A(\mathrm{kPa})$ & $32 \pm 24$ & $32 \pm 54$ & $32 \pm 84$ & $32 \pm 114$ \\
\hline \multirow{3}{*}{30} & Number of cycles $n$ & 1000 & 100 & 10 & 1 \\
& Cyclic load amplitude $V(\mathrm{~N})$ & $40 \pm 80$ & $40 \pm 100$ & $40 \pm 200$ & $40 \pm 300$ \\
& Cyclic stress amplitude $V / A(\mathrm{kPa})$ & $8 \pm 16$ & $8 \pm 20$ & $8 \pm 40$ & $8 \pm 60$ \\
\hline
\end{tabular}




\section{List of Figures}

1 CPT profiles from soil samples for full- and half-model tests . . . . . . . . . 39

2 T-bar profiles from soil samples (solid lines) for full-model tests (T-bar 1, 3 \& 4) and half-model tests (T-bar $2 \& 5$ ) including predictions of the present and previous tests (dash-dotted lines). . . . . . . . . . . . . . . . . . 40

3 Normalised penetration depths achieved following the self-weight penetration (SWP), suction installation (SI), and after static loading and unloading (SL/UL) in SoC. . . 41

4 History of vertical stresses and suction pressure during installation in SoC and uniform sand profiles (Data from Stapelfeldt et al. (2020)). . . . . . . . . . . . . . 42

5 Normalised resultant displacement contours (a) in the beginning and (b) close to the end of the suction suction and (c) after lid tough down in a SoC profile. . . . . 43

6 History of (a) drained and (b) rapid extraction resistance (solid lines) and relative suction pressure (dashed lines) in SoC profiles. . . . . . . . . . . . . . . . 44

7 History of normalised relative vertical displacements during cyclic loading packages $1,2 \& 3$ of load cases 10,20 , and $30 \ldots \ldots \ldots$. . . . . . . . . 45

8 History of (a) the applied stress, total stress and excess pore pressure at the lid invert during loading package 1, 2, and 3 and vertical stresses and history of (b) the excess pore pressure in test SoC-0.5-125SI-20. . . . . . . . . . . . . . . 46

9 Short and long term response and excess pore pressure at the lid invert during cyclic loading in test SoC-0.5-350J-10 . . . . . . . . . . . . . . . 47

10 The influence of the skirt wall thickness during vertical cyclic loading in SoC. . . . 48

11 History of vertical stresses and excess pore pressure at the lid invert during the long term (a) test SoC-0.5-350J-10 and (b) test SoC-0.5-100SI-30. . . . . . . . . . 49

12 History of vertical stresses and excess pore pressure at the lid invert during SoC-

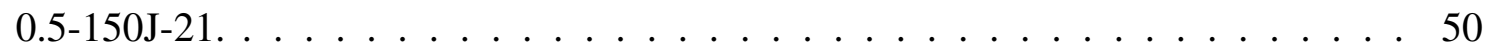

13 History of normalised relative vertical displacements during cyclic loading subjected to model caissons with aspect ratios of $L / D=0.5$ and $L / D=1$. 
14 History of vertical stresses and excess pore pressure at the lid invert during (a) test SoC-1.0-150SI-20 and (b) test SoC-1.0-125SI-21. . . . . . . . . . . . . 52

15 Normalised penetration depths achieved following the self-weight penetration (SWP), suction installation (SI), and after static loading and unloading (SL/UL) in CoS. . . 53

16 History of the vertical stresses and suction pressure during installation in $\mathrm{CoS}$ and uniform sand profiles (Data from Stapelfeldt et al. (2020)). . . . . . . . . . . . . . 54

17 Normalised resultant displacement contours during clay plug heave (a) without formation of a gap at $\Delta z / L=0.7$, (b) during the formation of a gap at $\Delta z / L=0.89$, (c) at the maximum opening of the gap at $\Delta z / L=0.90$ and (d) after the plug drop down at $\Delta z / L=0.91$ in a $\operatorname{CoS}$ profile. . . . . . . . . . . . . 55

18 History of the (a) drained and (b) rapid extraction resistance (solid lines) and suction pressure (dashed lines) in CoS profiles. . . . . . . . . . . . . 56

19 Normalised resultant clay plug displacement at (a) $\Delta z / L \geq 0.05$, and (b) $\Delta z / L \leq$ 0.1 of an undrained extraction test in a $\mathrm{CoS}$ profile. . . . . . . . . . . . 57

20 History of normalised relative vertical displacements during cyclic loading. . . . . 58

21 History of (a) vertical stresses and excess pore pressure at the lid invert during test CoS-0.5-350SI-10 and history of (b) the effective vertical load in $\mathrm{CoS}$ and uniform sand during loading package $2 \& 3$ (Data from Stapelfeldt et al. (2020)). . . . . . . 59

22 Comparison of (a) the influence the skirt wall thickness and (b) the development of the excess pore pressure at the lid invert during cyclic loading of test CoS-0.5-

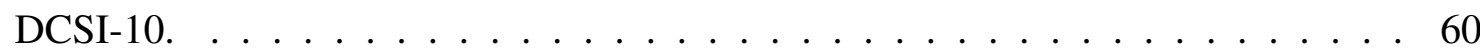

23 History of normalised relative vertical displacements during cyclic loading subjected to model caissons embedded in a $\mathrm{CoS}$ profile. . . . . . . . . . . . . . 61

24 History of vertical stresses and excess pore pressure at the lid invert during test CoS-0.5-350SI-20. . . . . . . . . . . . . . . . 62

25 History of (a) vertical stresses and excess pore pressure at the lid invert and (b) vertical displacements during cyclic loading package 2 of test CoS-0.5-350SI-11. . 63 
26 History of (a) vertical stresses and excess pore pressure at the lid invert and (b) vertical displacements during cyclic loading package 2 of test CoS-0.5-350SI-21. . 64 


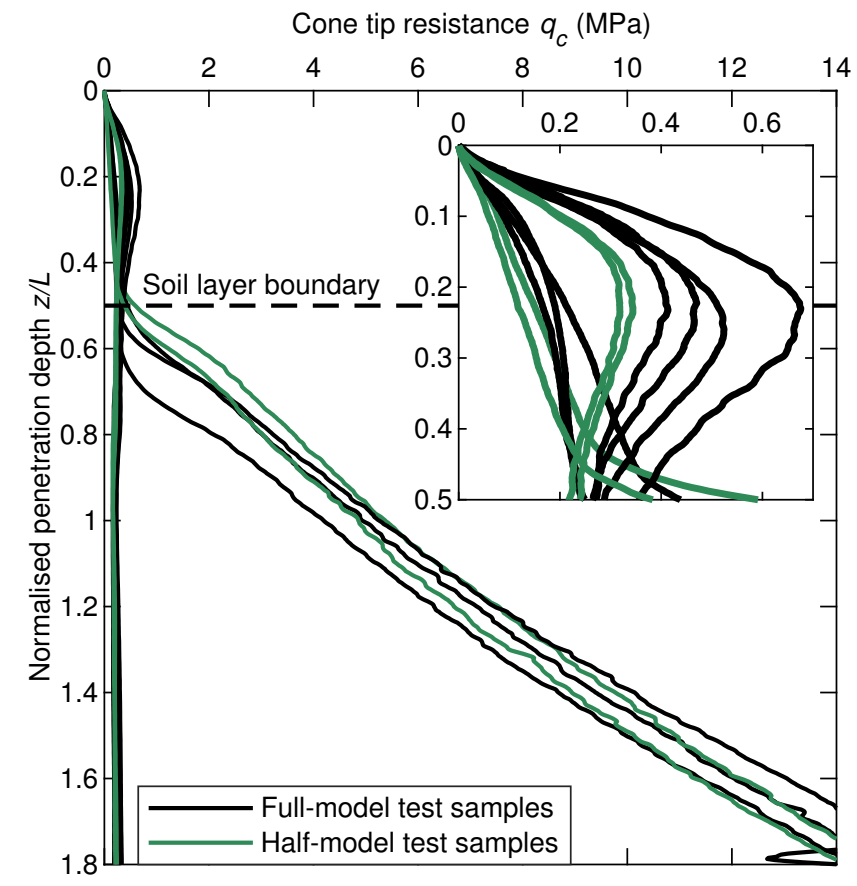

Fig. 1. CPT profiles from soil samples for full- and half-model tests 


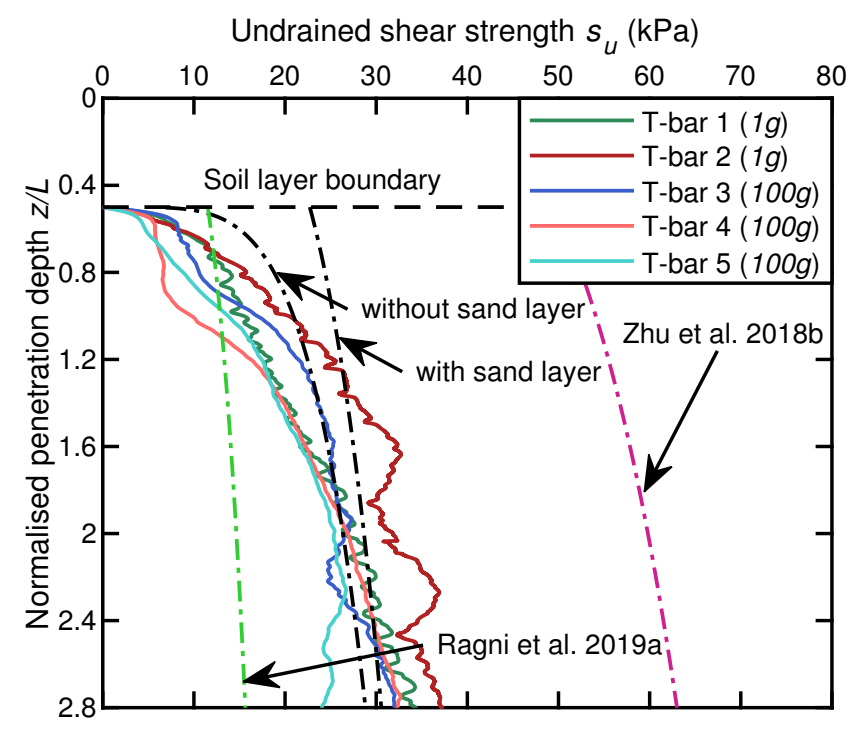

Fig. 2. T-bar profiles from soil samples (solid lines) for full-model tests (T-bar $1,3 \& 4$ ) and half-model tests (T-bar $2 \& 5$ ) including predictions of the present and previous tests (dash-dotted lines). 


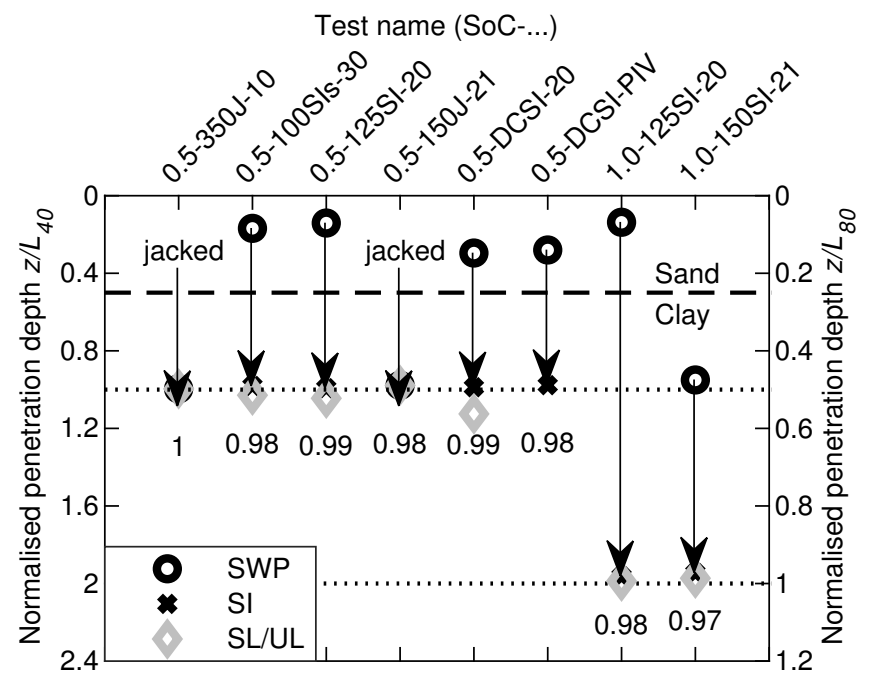

Fig. 3. Normalised penetration depths achieved following the self-weight penetration (SWP), suction installation (SI), and after static loading and unloading (SL/UL) in SoC. 


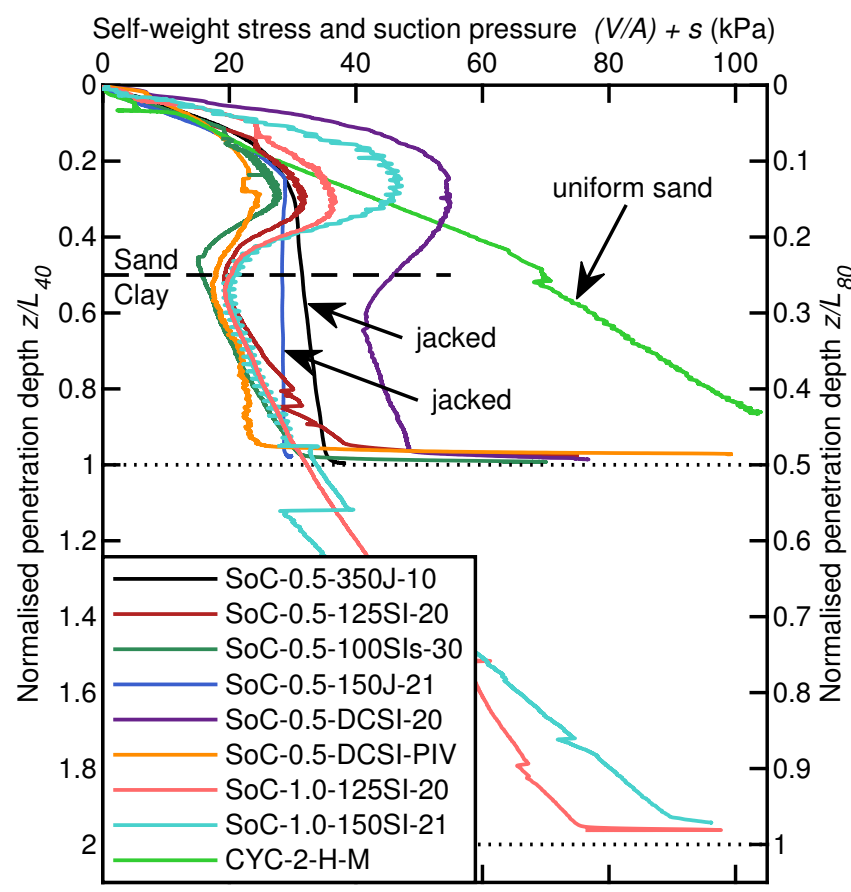

Fig. 4. History of vertical stresses and suction pressure during installation in SoC and uniform sand profiles (Data from Stapelfeldt et al. (2020)). 


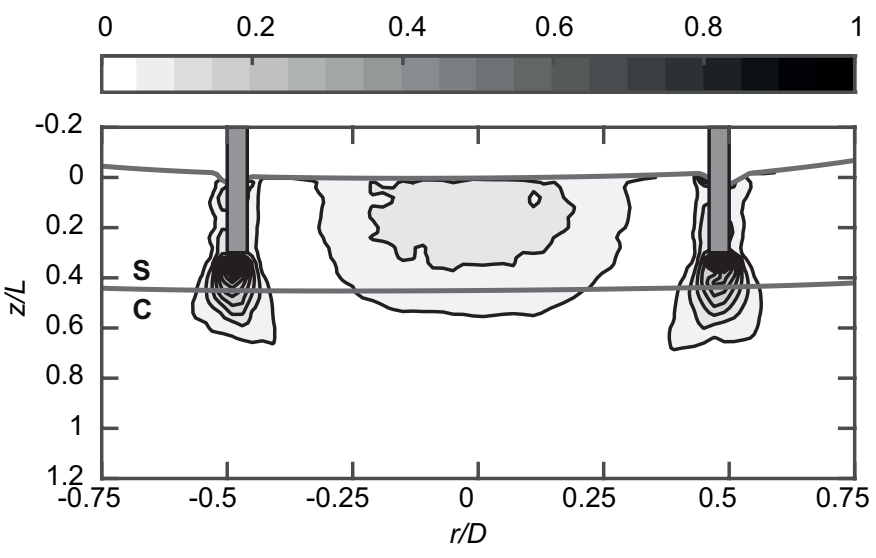

(a)

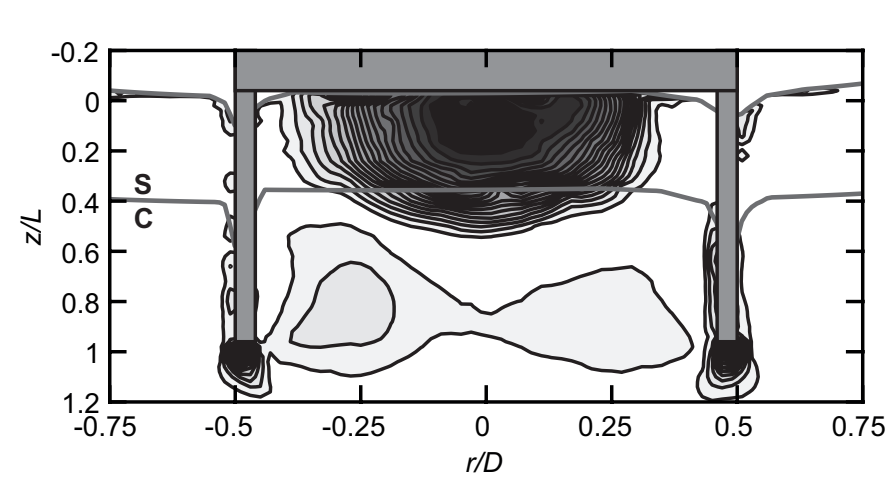

(c)

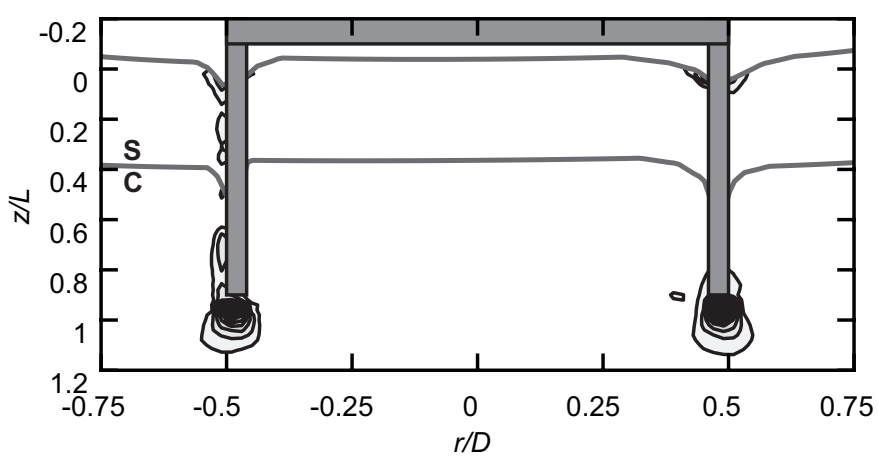

(b)

Fig. 5. Normalised resultant displacement contours (a) in the beginning and (b) close to the end of the suction suction and (c) after lid tough down in a SoC profile. 


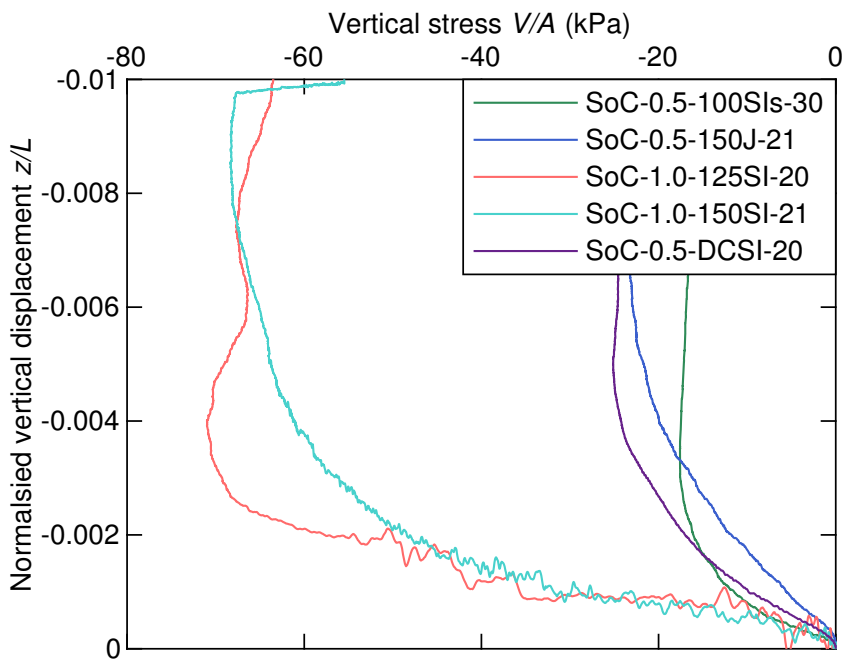

(a)

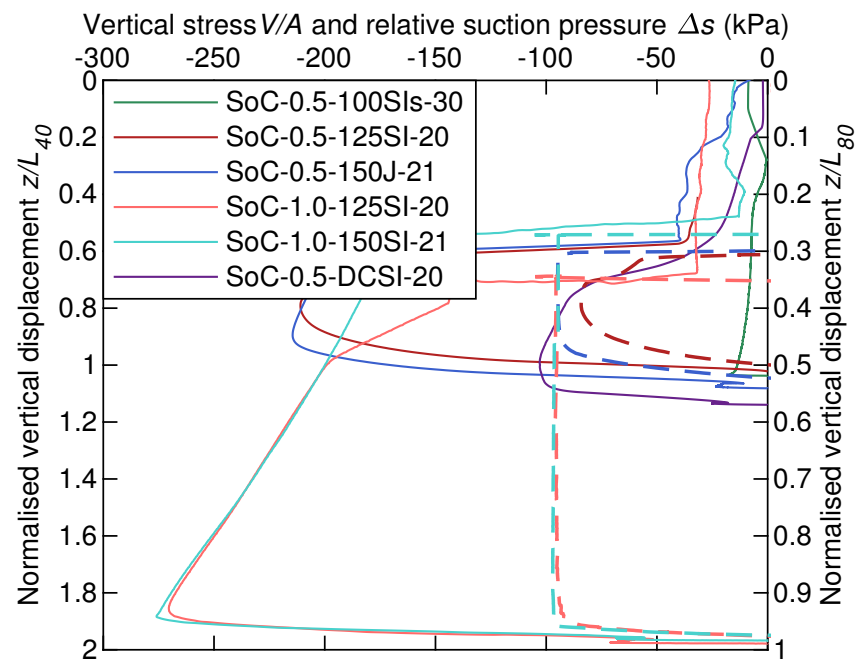

(b)

Fig. 6. History of (a) drained and (b) rapid extraction resistance (solid lines) and relative suction pressure (dashed lines) in SoC profiles. 


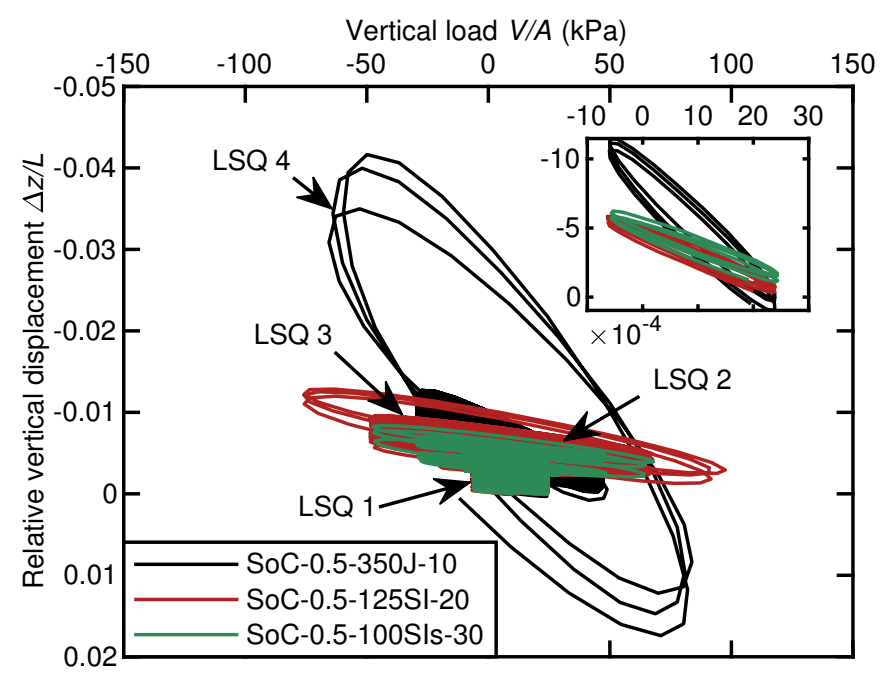

Fig. 7. History of normalised relative vertical displacements during cyclic loading packages 1,2 $\& 3$ of load cases 10, 20, and 30 . 


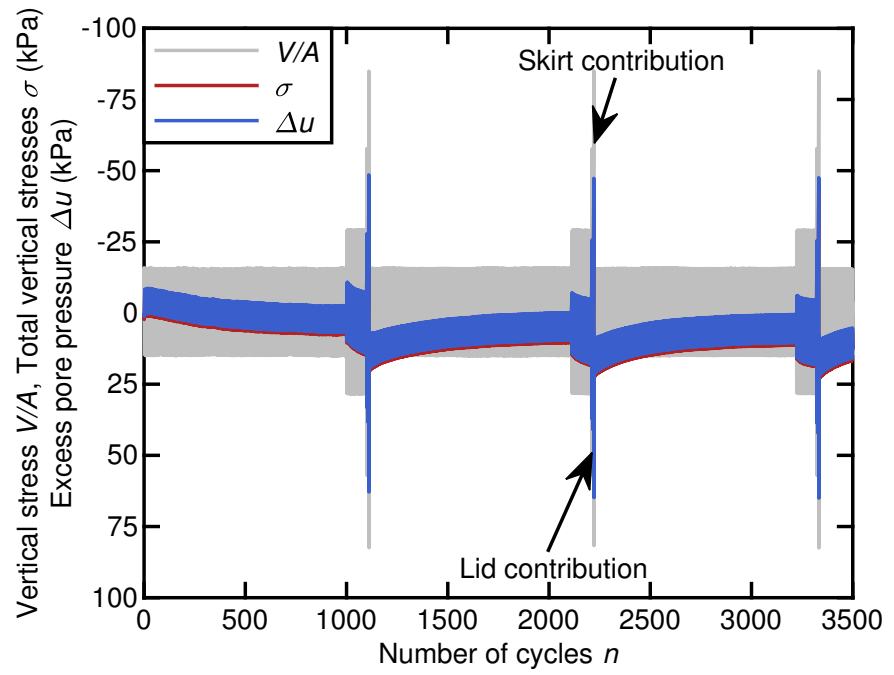

(a)

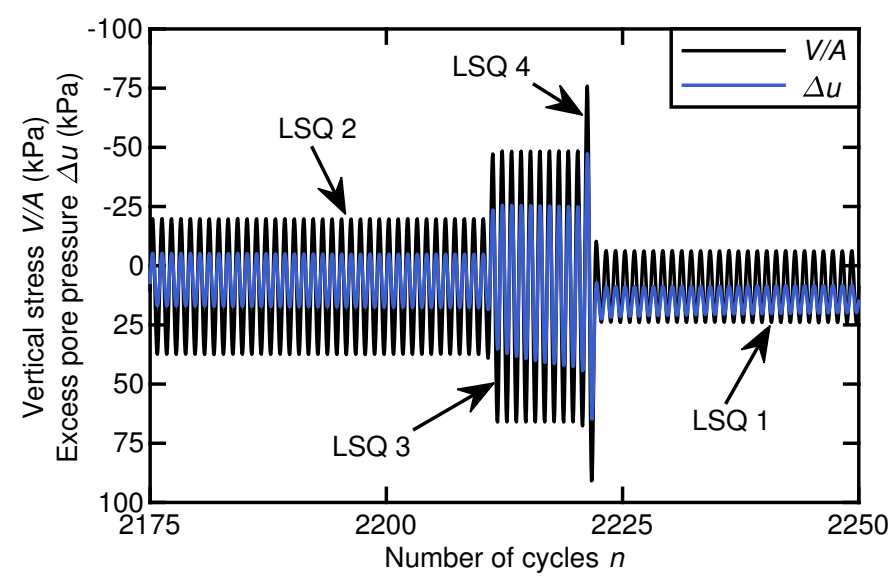

(b)

Fig. 8. History of (a) the applied stress, total stress and excess pore pressure at the lid invert during loading package 1,2, and 3 and vertical stresses and history of (b) the excess pore pressure in test SoC-0.5-125SI-20. 


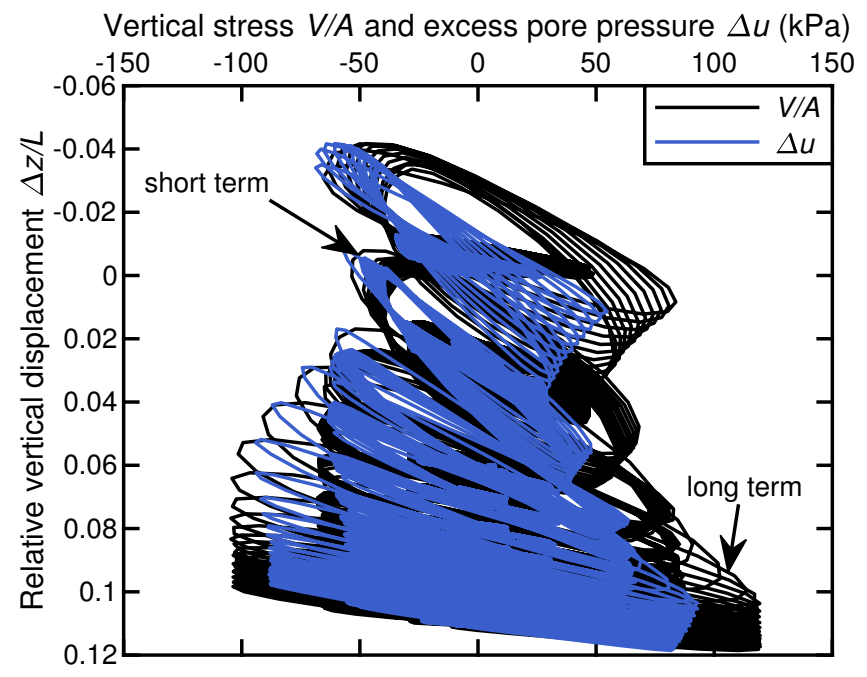

Fig. 9. Short and long term response and excess pore pressure at the lid invert during cyclic loading in test SoC-0.5-350J-10. 


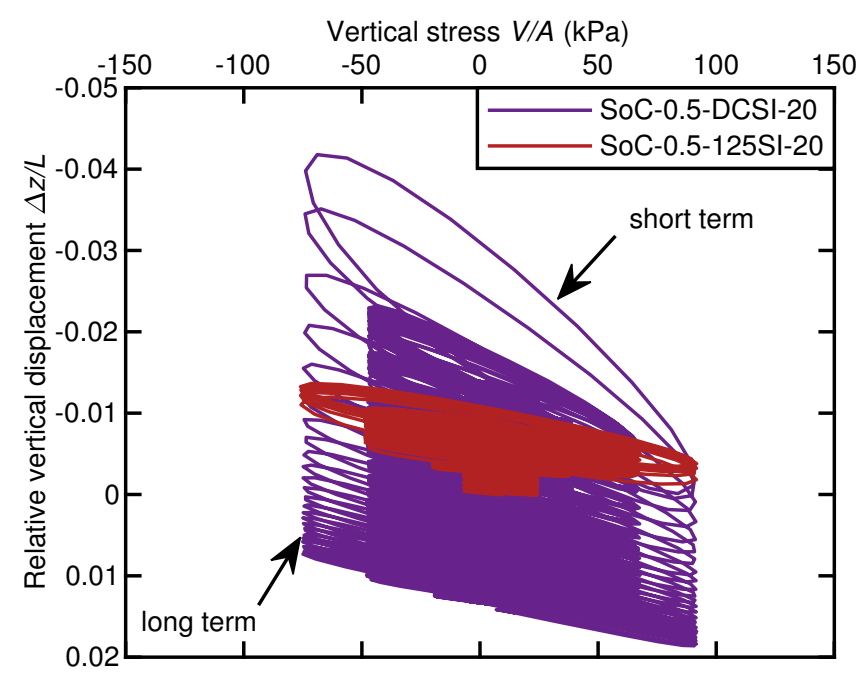

Fig. 10. The influence of the skirt wall thickness during vertical cyclic loading in SoC. 


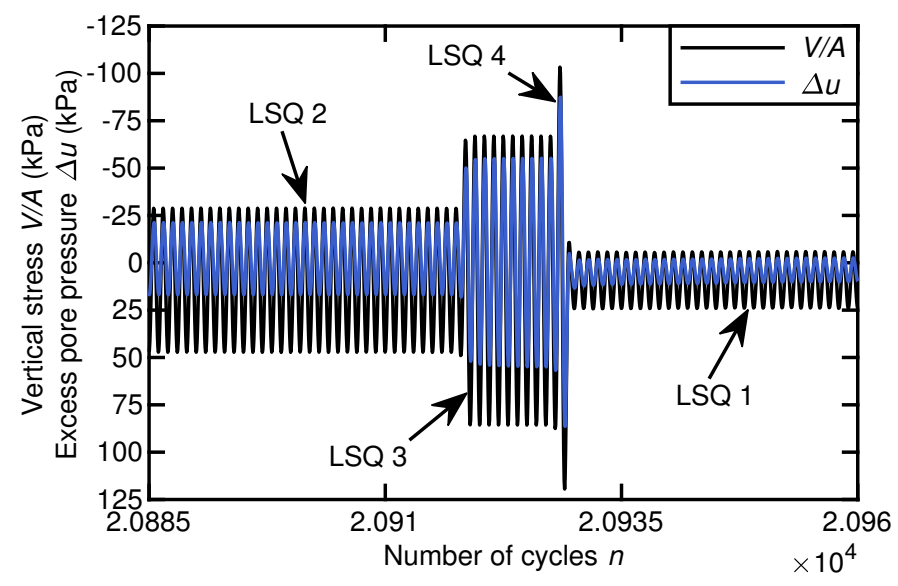

(a)

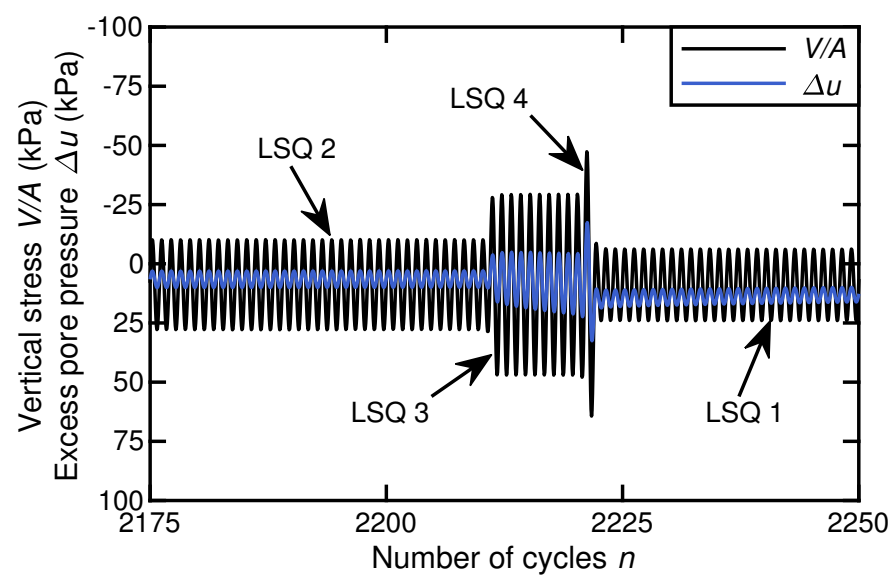

(b)

Fig. 11. History of vertical stresses and excess pore pressure at the lid invert during the long term (a) test SoC-0.5-350J-10 and (b) test SoC-0.5-100SI-30. 


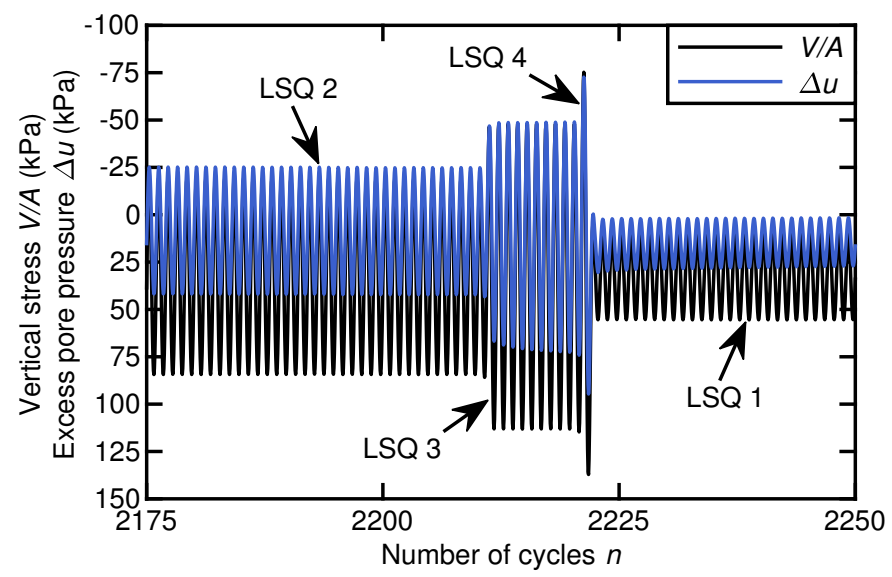

Fig. 12. History of vertical stresses and excess pore pressure at the lid invert during SoC-0.5-150J21. 


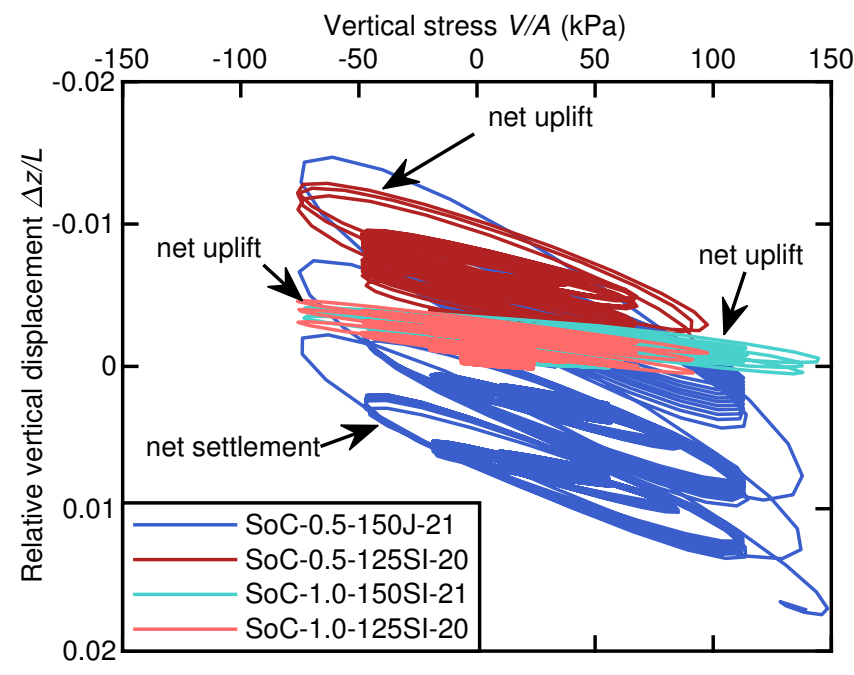

Fig. 13. History of normalised relative vertical displacements during cyclic loading subjected to model caissons with aspect ratios of $L / D=0.5$ and $L / D=1$. 


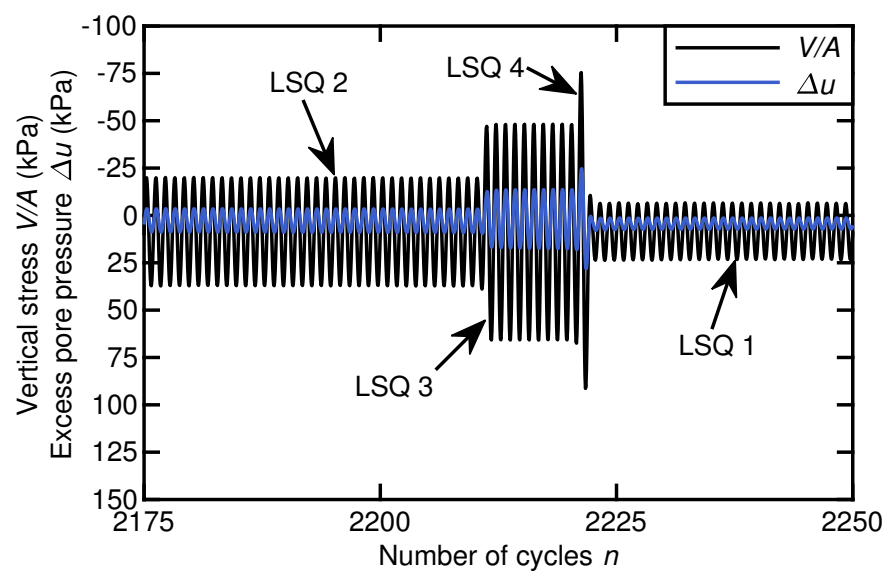

(a)

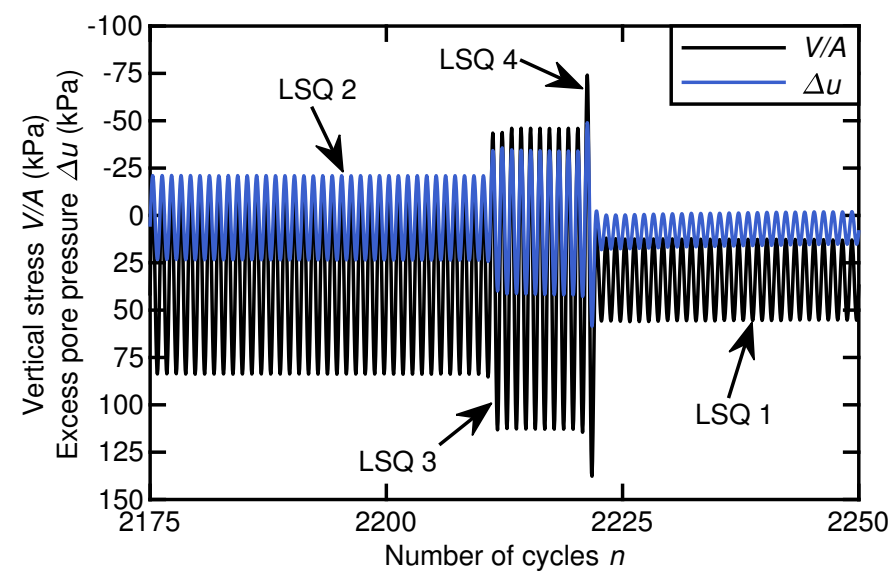

(b)

Fig. 14. History of vertical stresses and excess pore pressure at the lid invert during (a) test SoC-1.0-150SI-20 and (b) test SoC-1.0-125SI-21. 


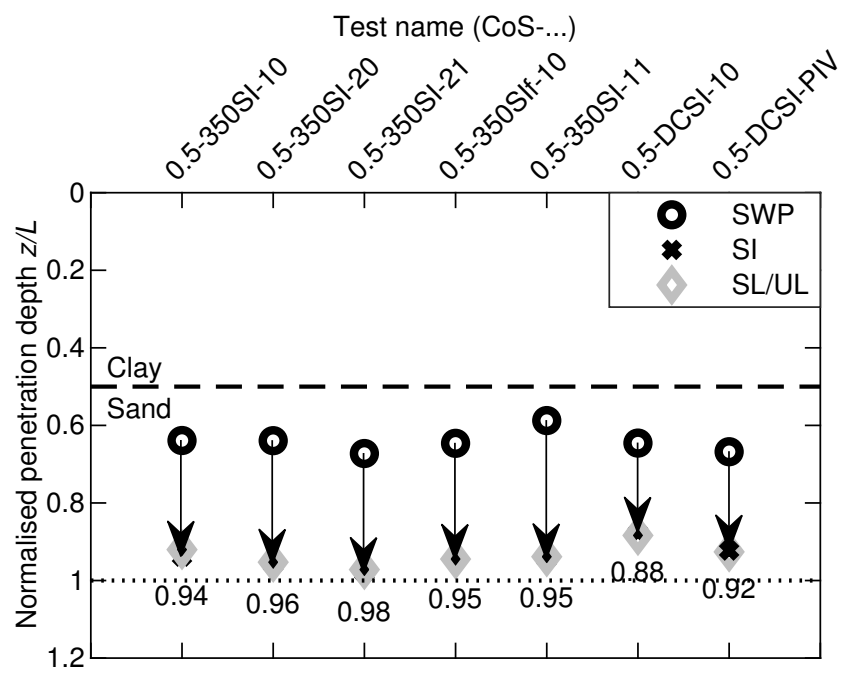

Fig. 15. Normalised penetration depths achieved following the self-weight penetration (SWP), suction installation (SI), and after static loading and unloading (SL/UL) in CoS. 


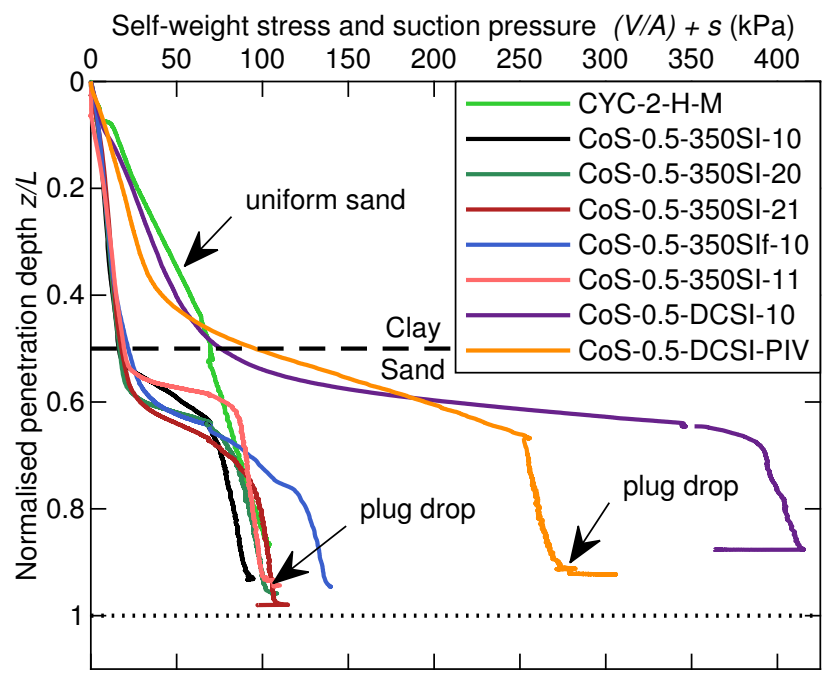

Fig. 16. History of the vertical stresses and suction pressure during installation in $\mathrm{CoS}$ and uniform sand profiles (Data from Stapelfeldt et al. (2020)). 


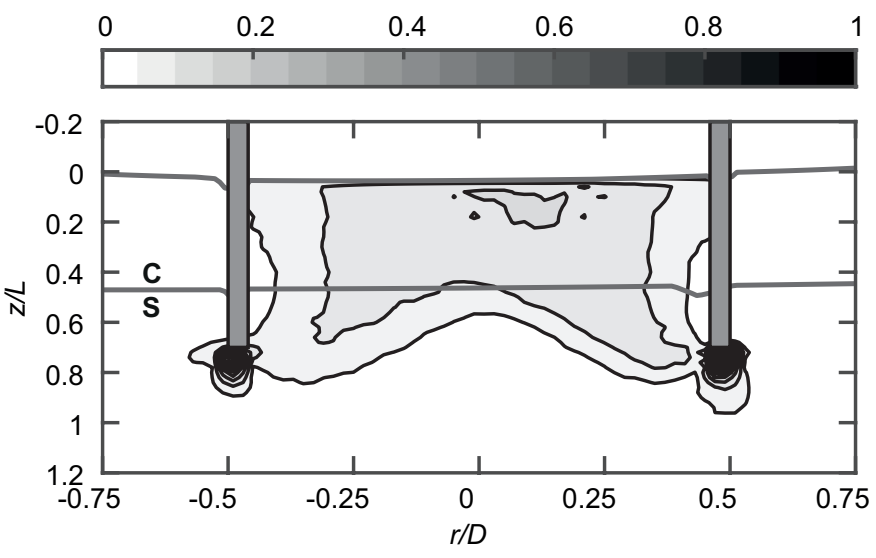

(a)

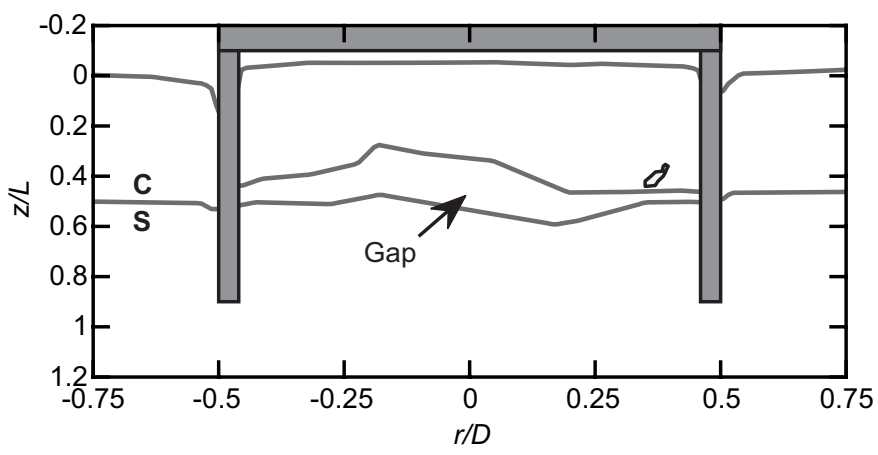

(c)

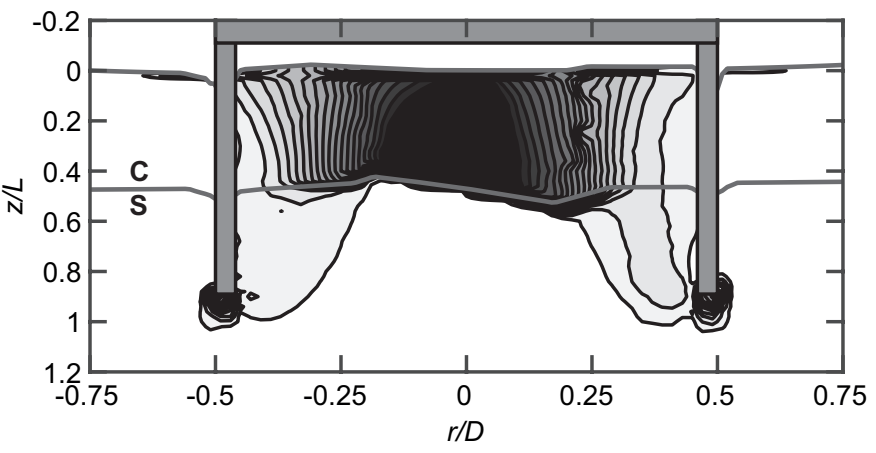

(b)

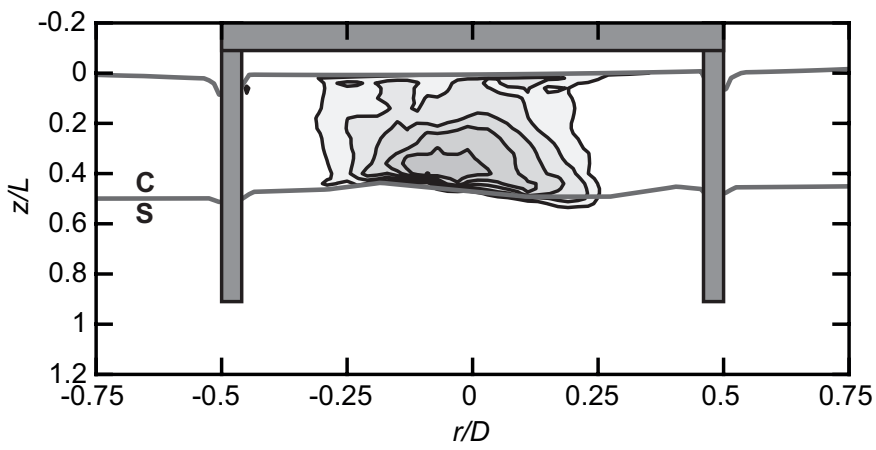

(d)

Fig. 17. Normalised resultant displacement contours during clay plug heave (a) without formation of a gap at $\Delta z / L=0.7$, (b) during the formation of a gap at $\Delta z / L=0.89$, (c) at the maximum opening of the gap at $\Delta z / L=0.90$ and (d) after the plug drop down at $\Delta z / L=0.91$ in a CoS profile. 


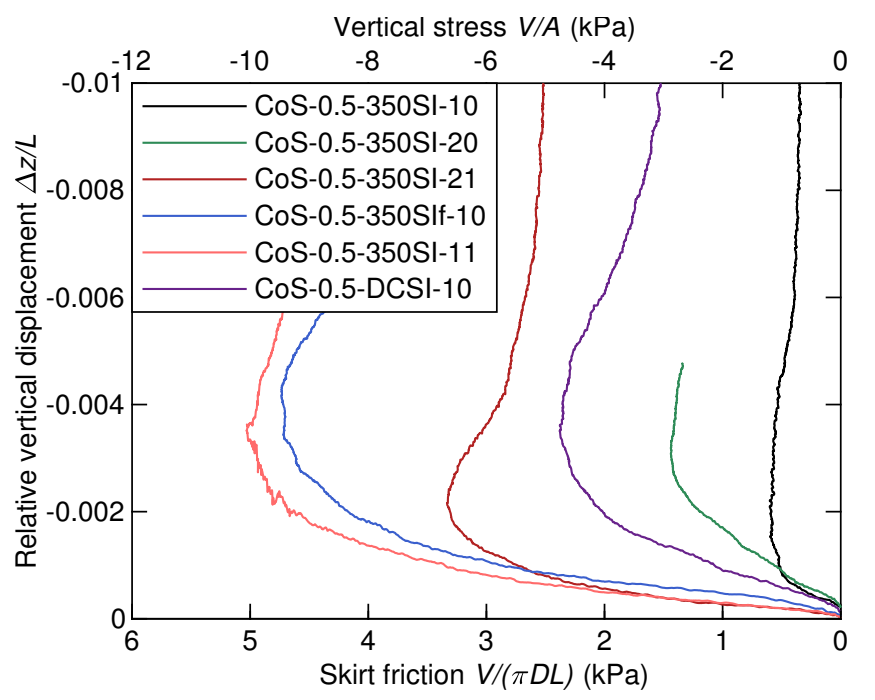

(a)

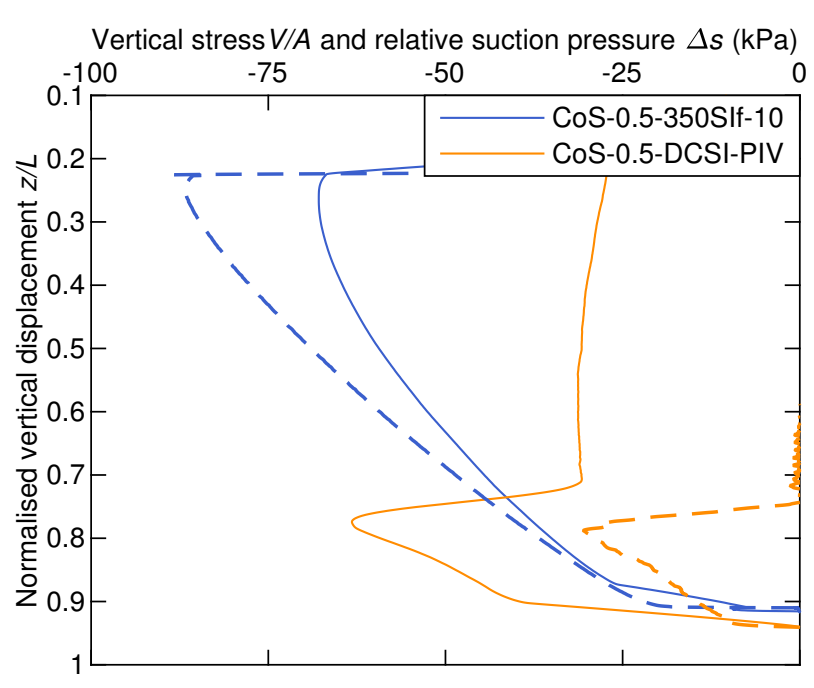

(b)

Fig. 18. History of the (a) drained and (b) rapid extraction resistance (solid lines) and suction pressure (dashed lines) in CoS profiles. 


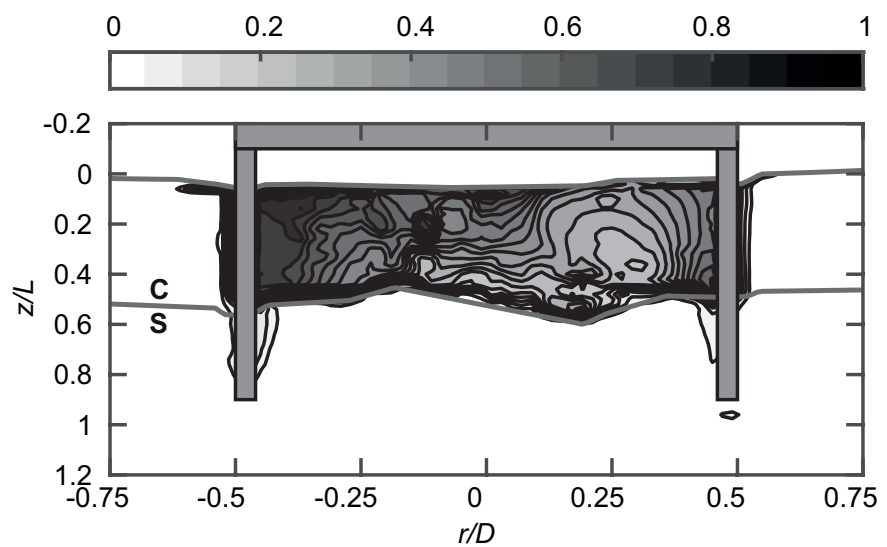

(a)

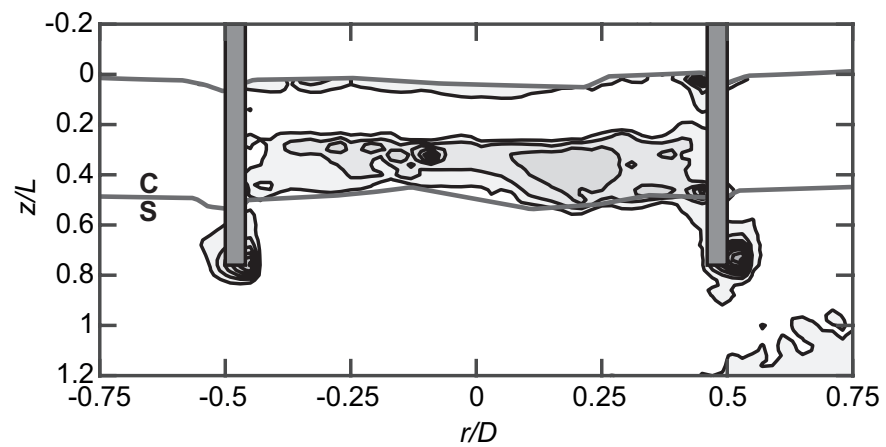

(b)

Fig. 19. Normalised resultant clay plug displacement at (a) $\Delta z / L \geq 0.05$, and (b) $\Delta z / L \leq 0.1$ of an undrained extraction test in a $\mathrm{CoS}$ profile. 


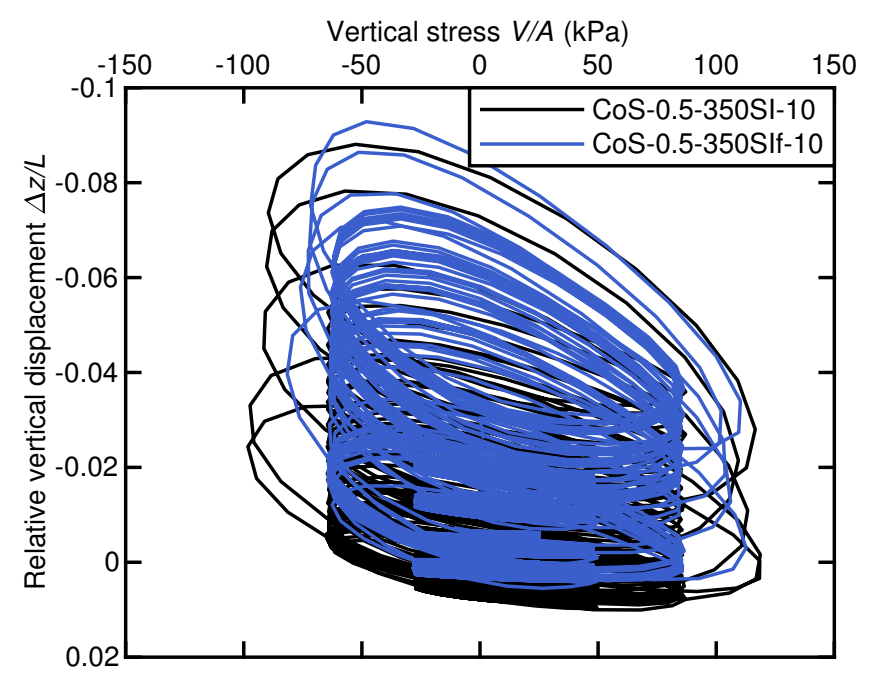

Fig. 20. History of normalised relative vertical displacements during cyclic loading. 


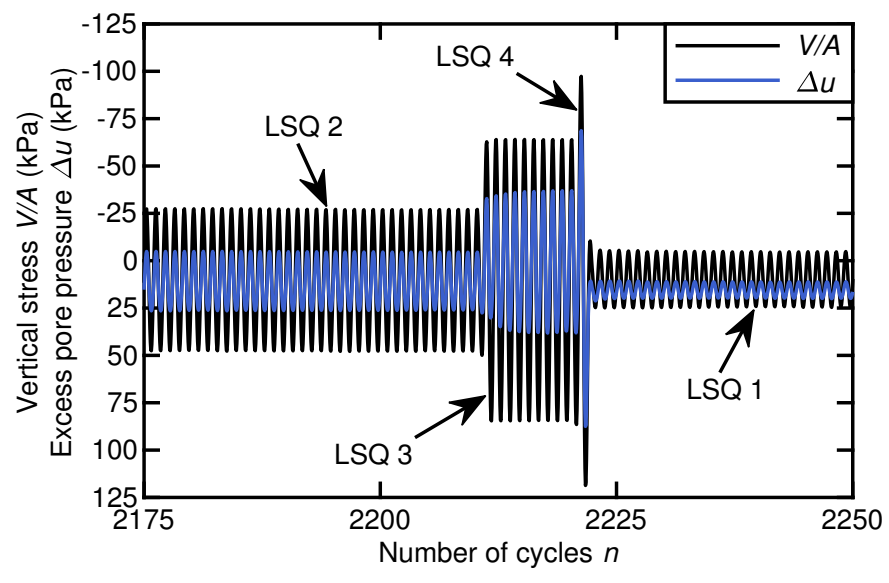

(a)

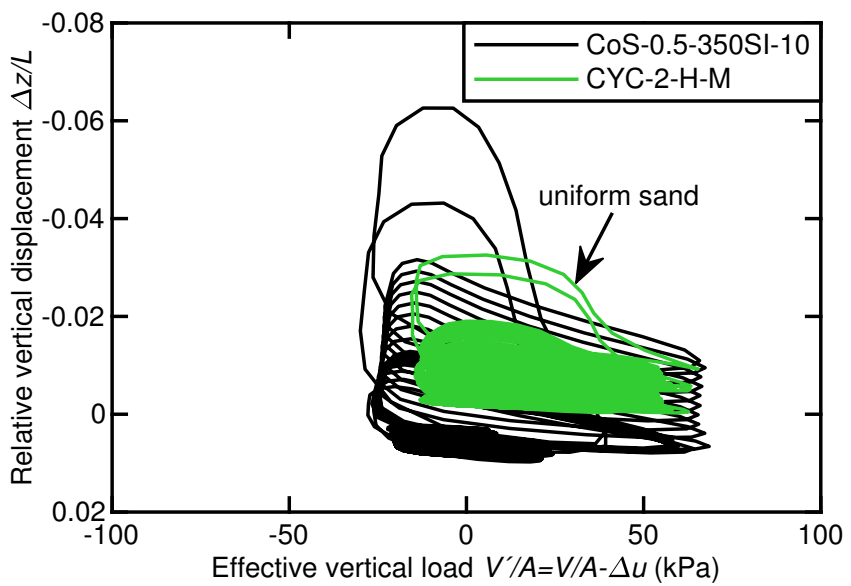

(b)

Fig. 21. History of (a) vertical stresses and excess pore pressure at the lid invert during test CoS0.5-350SI-10 and history of (b) the effective vertical load in CoS and uniform sand during loading package $2 \& 3$ (Data from Stapelfeldt et al. (2020)). 


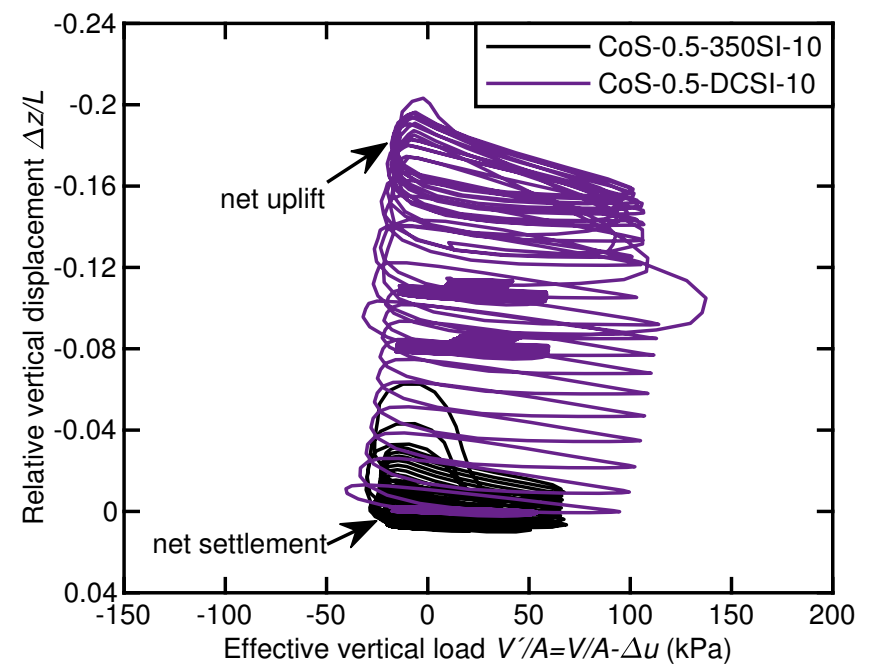

(a)

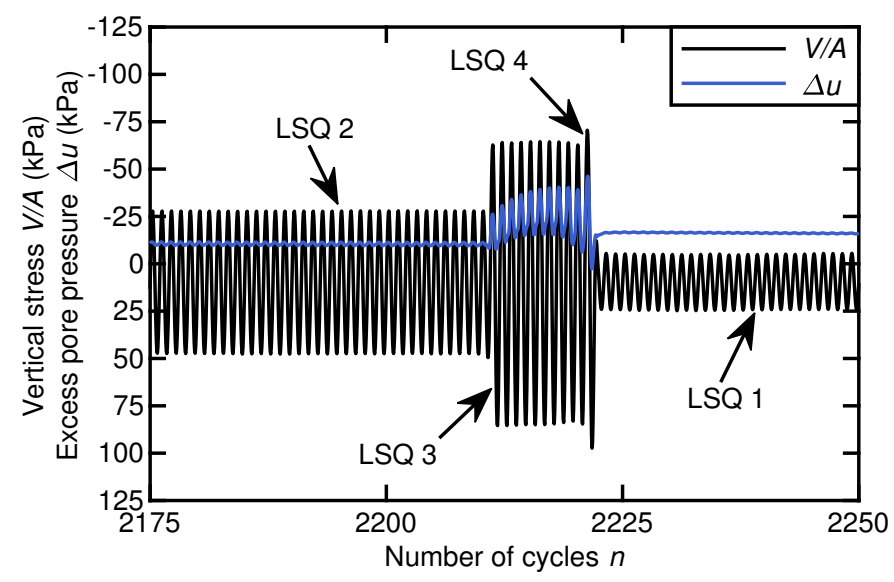

(b)

Fig. 22. Comparison of (a) the influence the skirt wall thickness and (b) the development of the excess pore pressure at the lid invert during cyclic loading of test CoS-0.5-DCSI-10. 


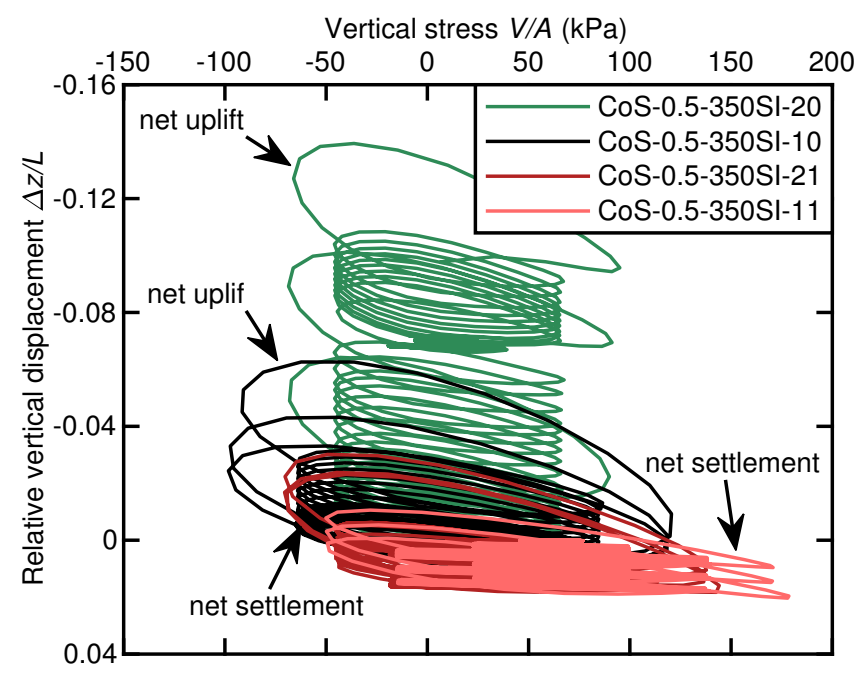

Fig. 23. History of normalised relative vertical displacements during cyclic loading subjected to model caissons embedded in a $\mathrm{CoS}$ profile. 


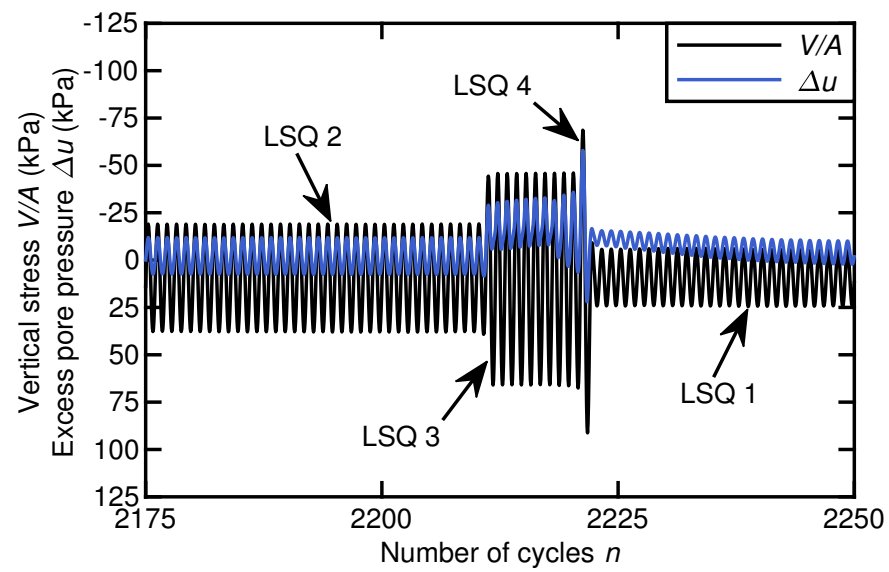

Fig. 24. History of vertical stresses and excess pore pressure at the lid invert during test CoS-0.5350SI-20. 


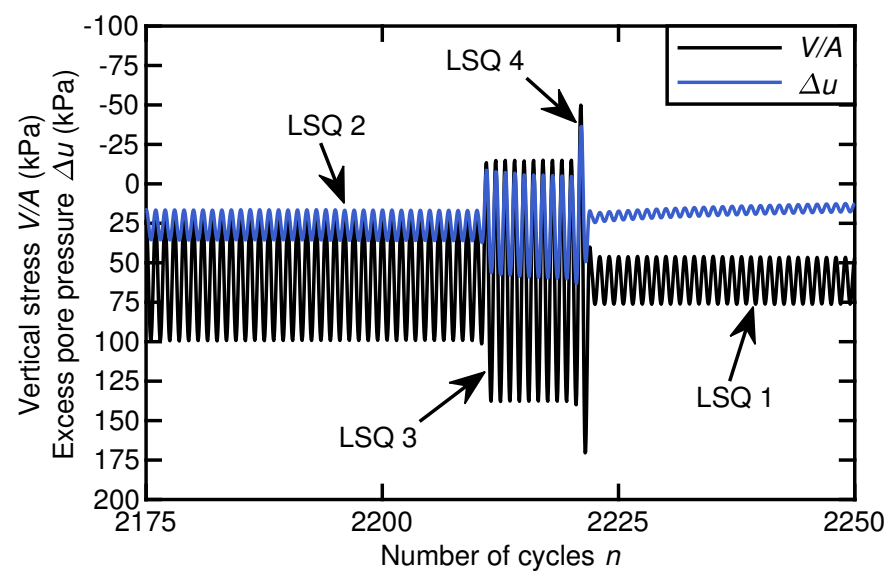

(a)

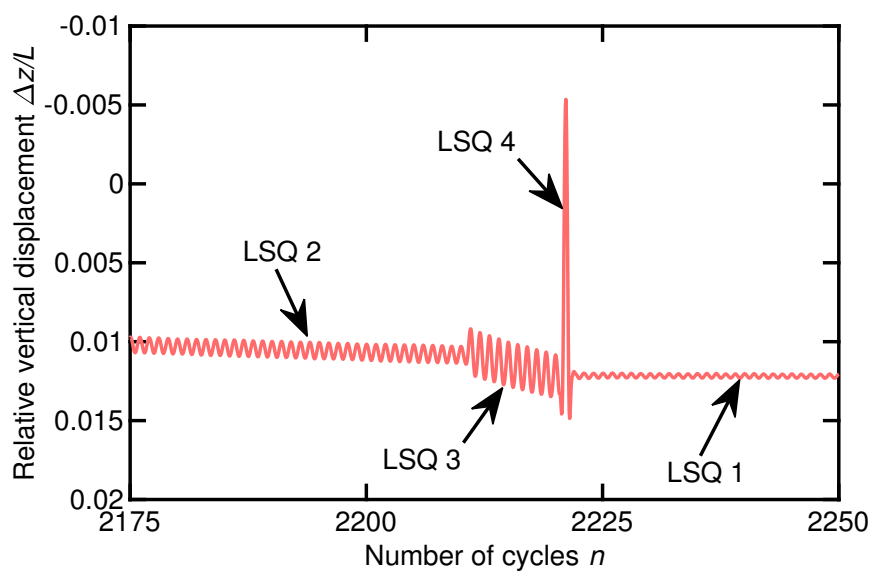

(b)

Fig. 25. History of (a) vertical stresses and excess pore pressure at the lid invert and (b) vertical displacements during cyclic loading package 2 of test CoS-0.5-350SI-11. 


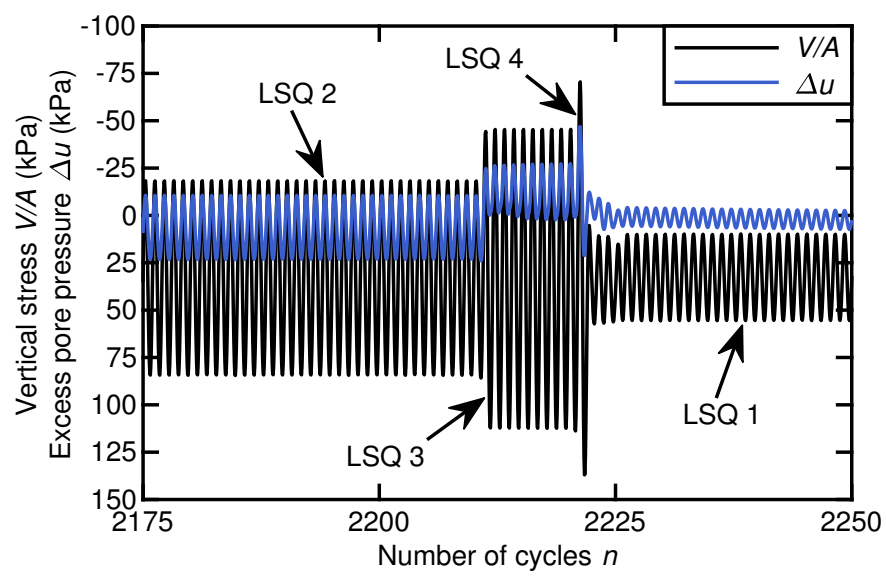

(a)

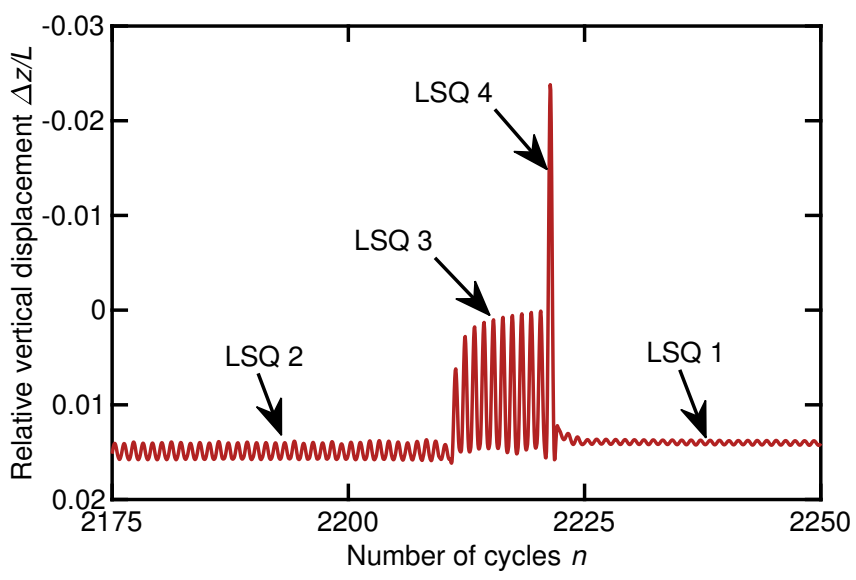

(b)

Fig. 26. History of (a) vertical stresses and excess pore pressure at the lid invert and (b) vertical displacements during cyclic loading package 2 of test CoS-0.5-350SI-21. 